\title{
Representing and encoding plant architecture: A review
}

\author{
Christophe Godin*
}

CIRAD, Programme de modélisation des plantes, BP. 5035, 34032 Montpellier Cedex 1, France

(Received 25 February 1999; accepted 1 December 1999)

\begin{abstract}
A plant is made up of components of various types and shapes. The geometrical and topological organisation of these components defines the plant architecture. Before the early 1970's, botanical drawings were the only means to represent plant architecture. In the past two decades, high-performance computers have become available for plant growth analysis and simulation, triggering the development of various formal representations and notations of plant architecture (strings of characters, axial trees, tree graphs, multiscale graphs, linked lists of records, object-oriented representations, matrices, fractals, sets of digitised points, etc.). In this paper, we review the main representations of plant architecture and make explicit their common structure and discrepancies. The apparent heterogeneity of these representations makes it difficult to collect plant architecture information in a generic format to allow multiple uses. However, the collection of plant architecture data is an increasingly important issue, which is also particularly time-consuming. At the end of this review, we suggest that a task of primary importance for the plant-modelling community is to define common data formats and tools in order to create standard plant architecture database systems that may be shared by research teams.
\end{abstract}

\section{plant architecture / geometry / topology / scales of representation / encoding}

Résumé - Représentation et codage de l'architecture des plantes. Une plante est constituée d'entités ayant des types et des formes variés. L'organisation géométrique et topologique de ses entités définit «l'architecture de la plante». Avant le début des années 70, la seule façon de représenter l'architecture des plantes était de faire des dessins botaniques précis. Dans les deux dernières décennies, l'utilisation d'ordinateurs de plus en plus puissants a permis de concevoir des modèles de simulation de croissance de plante capables de produire des architectures détaillées et de les visualiser. Ceci a favorisé l'émergence d'un ensemble varié de méthodes de représentation de l'architecture des plantes (chaines de caractères, «axial trees », graphes arborescents, graphes multi-échelles, listes chaînées, représentations objet, matrices, fractales, ensemble de points digitalisés, etc.). Dans ce papier, nous passons en revue les principales représentations de l'architecture des plantes, en insistant sur leurs spécificités, mais aussi sur leurs points communs. L'hétérogénéïté apparente de ces représentations rend la collecte des informations décrivant l'architecture des plantes difficilement réutilisable. Toutefois, la mesure de «données architecturales» est un élément d'une importance capitale dans la conception de modèles structure/fonction. C'est aussi une tâche particulièrement longue et fastidieuse. C'est pourquoi nous suggérons à l'issue de cette revue, qu'une action de première importance à mener dans la communauté de modélisation est de définir des formats de données et des outils communs pour créer des bases de données architecturales standard. Ces bases de données pourraient être spécifiées, recueillies et exploitées par différentes équipes de recherches, factorisant ainsi les efforts et se dottant des moyens de comparer leurs résultats sur des bases communes.

architecture des plantes / géometrie / topologie / échelles de représentation / codage

\footnotetext{
* Correspondence and reprints
}

Tel. 04675938 62; Fax.04675938 58; e-mail: godin@cirad.fr 


\section{INTRODUCTION}

Representations of plant architecture are commonly used to model plant structure and function, e.g. carbon partitioning, water transfer, root uptake and growth, architectural analysis, interaction with the microenvironment, wood mechanics, ecology and developmental or visual models. Because the languages and aims are quite different from one application to another, a wide variety of representations have been proposed, using different formalisms and having different properties. The aim of this paper is to provide guiding principles to bring some order to these numerous plant architecture representations. A similar approach was followed for plant growth models by Kurth [73], who proposed a classification of the models into 3 main categories: aggregated (statistical models of populations), morphological (making use of plant modularity) and process (physiological based) models. Similarly, Thornley, Johnson [121] and Prusinkiewicz [92], proposed that computer models be divided into empirical (descriptive) and causal (mechanistic, physiologically based). Room et al. [103] proposed a classification based on the presence or absence of topological and geometric information in models. This paper proposes a new way to group models based on the classification of the methods used to represent plant architecture. This classification is itself based on the level of structural detail of the plant representation.

Although the notion of plant architecture is frequently used in the literature, there is no universally agreed definition. The understanding of this concept varies depending on context. A few authors use the term architecture explicitly. According to Hallé et al. [61], the phrase "plant architecture" is frequently used to refer to the architectural model of a tree species, i.e. the description of the growth patterns of an ideal individual of a species, e.g. [11, 14, 20, 21, 40, 44, 99] or in modelling domains, $[33,35,47,97]$. In this context, plant architecture refers to a set of rules that express the structure and growth of individuals in some identified group on average in non limiting conditions. However, the phrase can also be used in the same context to refer to the structural expression of the growth process of a given individual. In this case, the term "plant architecture" denotes the 3-dimensional structure of an individual, and includes both the topological arrangement of the plant components and their coarse geometric characters (e.g. orthotropic vs. plagiotropic components). This second meaning is closer to that proposed by Ross [104], for whom plant architecture is taken to mean "a set of features delineating the shape, size, geometry and external structure of a plant", hence putting considerable emphasis on the geometry of individuals $[110,117]$. Similar meanings are used in several other fields of plant research, e.g. hydraulics [123, 132], plant growth modelling [36], plant measurement [112, 115], and in carbon partitioning [88].

In compliance with these latter definitions, I shall use the term plant architecture in this paper to denote the structure of an individual plant crown and/or root system. This is intended to emphasise the difference with the concept of an architectural model mentioned above. More precisely, in order to encompass the various usages of the term in the different application fields, I shall consider plant architecture as any individual description based on decomposition of the plant into components, specifying their biological type and/or their shape, and/or their location/orientation in space and/or the way these components are physically related one with another.

According to this definition, a representation of plant architecture contains at least one of the following types of information:

- Decomposition information, describing how the plant is made up of several components, possibly of different types;

- Geometrical information, describing the shapes and spatial positions of components. Here, the components are considered independently one from another;

- Topological information ${ }^{1}$, describing which components are connected with others. This information expresses a notion of hierarchy among the components of a branching system.

These sources of information may be combined to form a representation of plant architecture, leading to more or less complex descriptions. In this paper, plant architecture representations are discussed according to the complexity of their decomposition into components. At the lowest level of complexity, plant architectures are considered as a whole, and the fact that plants are modular organisms $[12,60,63,128]$ is not taken into account in the representation. These global representations are described in section 2. By contrast, modular representations rely on specific decomposition of a plant into modules of a particular type (e.g. internodes, growth units, axes or branching systems). These representations, which correspond to an intermediate level of structural complexity, are described in section 3. A third level of structural complexity can be defined when plants are decomposed into a hierarchy of modules having different sizes. The resulting multiscale representations are described in section 4 . The final section discusses the properties of these representations from a modelling perspective and concludes that standard data formats and tools need to be defined.

\footnotetext{
${ }^{1}$ This adjective is not used in the conventional mathematical sense. It is widely used in the context of plant modelling to denote the connectedness properties of branching structures.
} 
In this paper, descriptions of plant architectures are considered within a limited range of scales. At the finest scale, descriptions of rings in the wood e.g. see [18], tissues e.g. [76] or vascular systems [3] are not considered. At the coarsest scale, the review is restricted to the representation of individual plants. Representations of stands or forests [16], orchards [69] or plant eco-systems e.g. [38] are not addressed.

\section{GLOBAL REPRESENTATIONS}

The first approach consists of representing the plant (or the plant functions) as a whole, not decomposed into modules. Rather, modules (or organs) of similar types are considered as a whole which bears a global function (water uptake, transport, photosynthesis, etc.). The plant architecture is thus represented by one or several compartments

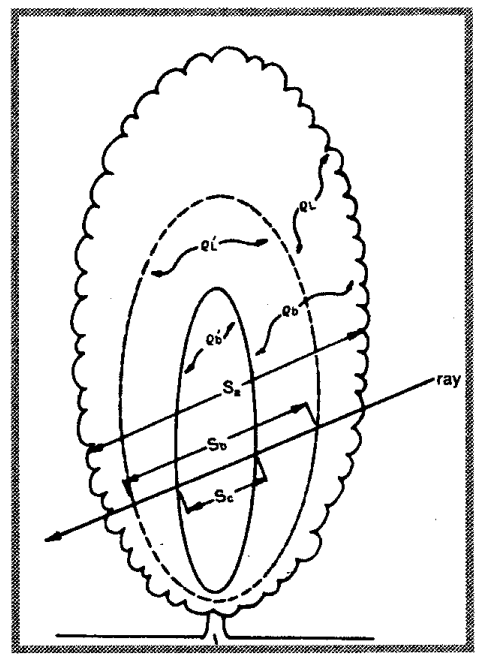

$\mathbf{a}$

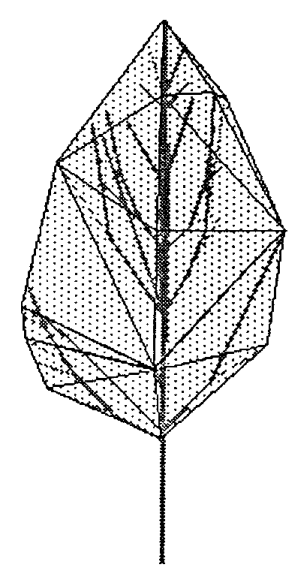

c

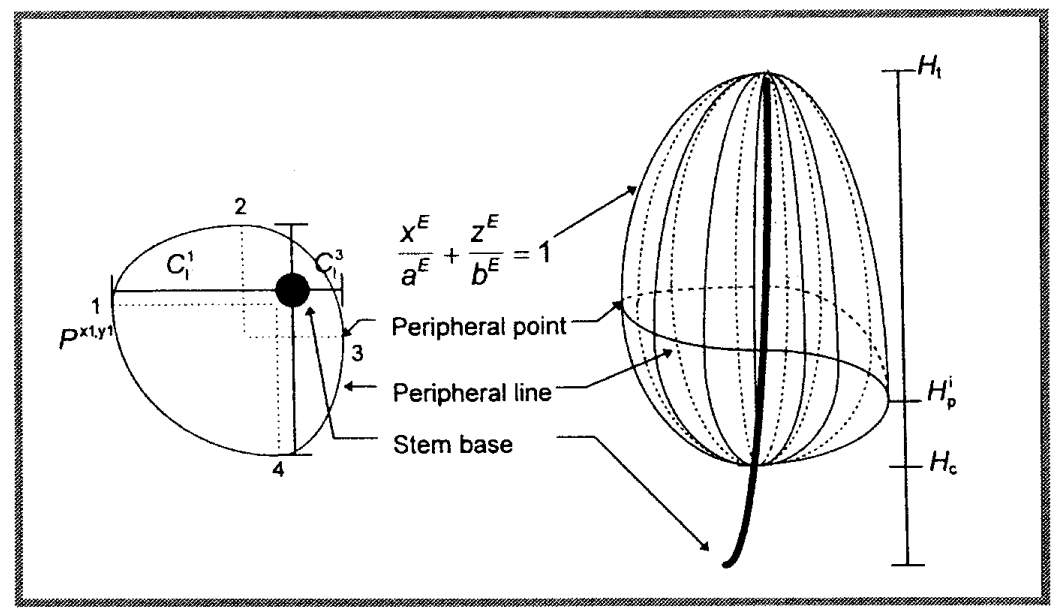

b

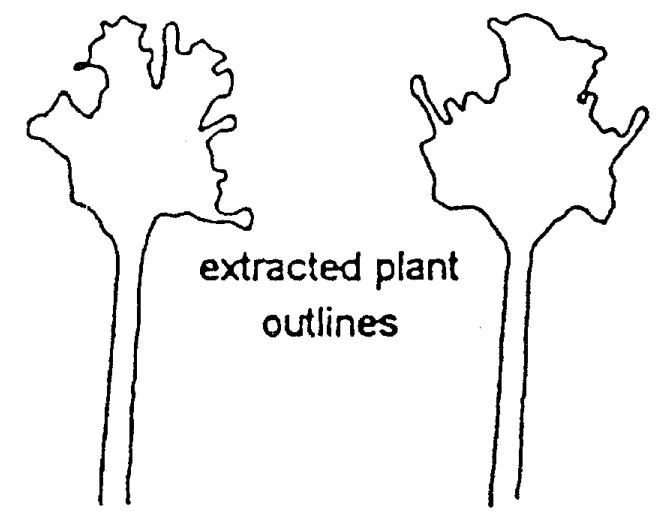

front image

Figure 1. Global geometric representations of plant architecture using a. simple parametric model (from [84]) b. complex parametric model (from [22]) c. a non-parametric model (from [26]) d. a contour description (from [106]). 
whose functions are defined by a global model. These global representations can be divided into two categories.

\subsection{Geometric representations}

At a global scale, geometric representations of crowns are used to model plant/environment interactions. Two types of geometric representations can be distinguished.

A simple and economic representation of plant geometry can be constructed using parametric representations. Spheres or ellipses are used for instance to model light interception by tree crowns [84] (figure 1a). Cylinders, cone frustums or paraboloids are used to study the mechanical properties of plants [6] or in forestry applications to model trunk or crown shapes e.g. [81]. In order to account for wider spectra of shapes, these simple parametric representations can be refined by using more complex geometric models, i.e. containing slightly more parameters. Cescatti [22], for instance, introduced an asymmetric geometric model of the tree crown to account for the variability of crown shapes in a forest stand (figure $1 b$ ).
In other studies, flexibility in the geometric representation is achieved by using non-parametric models. Cluzeau et al. [26] explored the use of a polyhedral representation of crown shape (figure 1c). According to these authors, such a representation "is intermediate in terms of computation costs and efficiency between classical geometric shapes and more elaborated computer graphic representations". Another example is provided by the non-parametric reconstruction of shapes from photographs. Shimizu and Heins [106] for instance use photogrametry techniques and edge detection algorithms to compute the connected outlines of a vervain plant from photographs (figure 1d).

\subsection{Compartment representations}

Compartment-based approaches are intended to model exchanges of substances within the plant at a global scale. Plants are decomposed into two or more compartments representing sinks or sources for substance transfer within the plant or at the interface between the plant and its

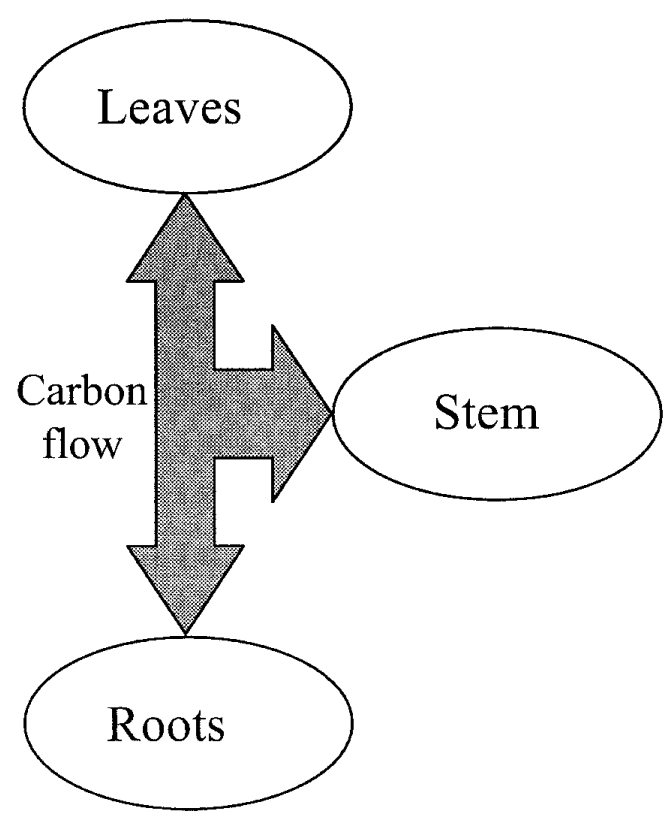

a

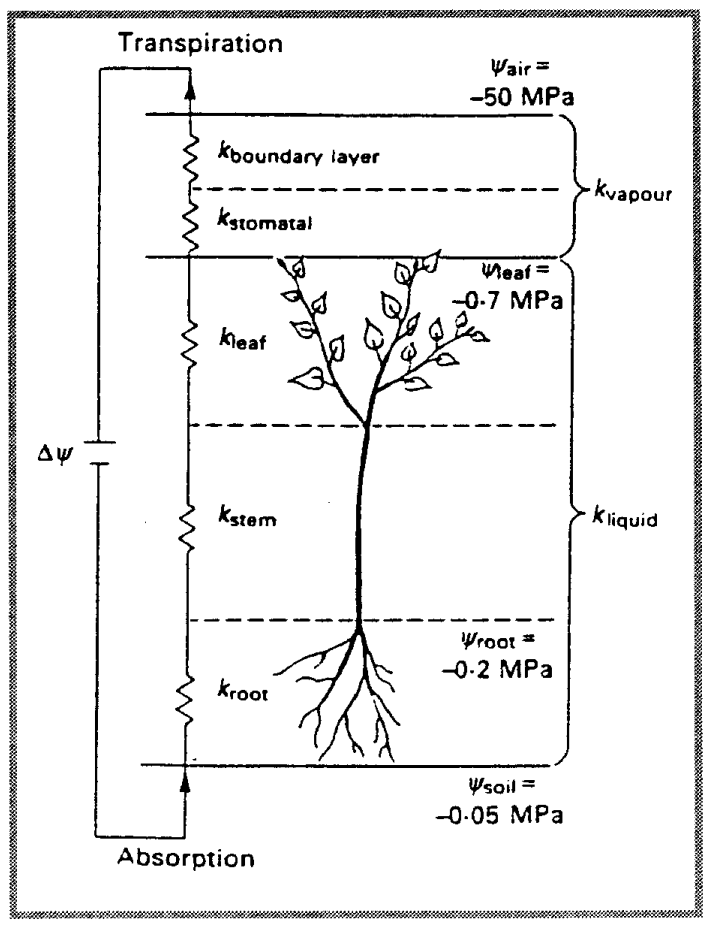

b

Figure 2. Compartment representations of plant architecture a. in carbon partitioning models. Compartments are represented by different pools of carbon. b. in water transport models, compartments are associated with conductances $k$ (from [123]). 
environment. Compartment representations may be considered as coarse topological descriptions of the plant architecture. A compartment may, for example, correspond to pools of leaves, roots, fruits or wood with connections between one another. In these pools, the organs are not differentiated one from another. They are considered as biomass with certain global properties (photosynthetic efficiency, mass, temperature, transfer rates, etc.). The first compartment models were introduced to model the diffusion of assimilates in plants [119, 120]. These models initially contained a leaf and a root compartment and described exchanges between these compartments using differential equations. Since then, compartment models have undergone substantial development $[15,77$, $80,124]$ and have given rise to extensions containing additional compartments to refine the modelling of element exchanges within the plant. A stem compartment can be added, for instance, to model the growth process of the stem and to take into account the consumption of assimilates in the diffusion process [37] (figure 2a). Similarly, to model water transport, plants are represented as a series of compartments at the interface between the soil and the atmosphere. Each compartment has a specific hydraulic conductivity and the flow of water through the plant results from the difference in water potential between the surface of the leaves and the soil/roots [41, 116] (figure 2b).
To summarise, global representations of plant architecture are representations of either plant geometry or topology at a coarse scale. They allow the modeller to design parsimonious models, i.e. models with a small number of parameters, which in turn favours a biological interpretation of the model structure. However, for many applications such as studying microclimate, assimilate repartition, wood properties, or fruit production in plant crowns, visualising the branching structure of a plant architecture, simulating crown development etc., these models are considered too reductive since they oversimplify the plant architecture. In such cases, more complex representations have to be considered.

\section{MODULAR REPRESENTATIONS}

This step towards refined representation is based on the consideration of plants as modular organisms: plants are made up by the repetition of certain types of components [10, 13, 61, 63]. Modular representations rely on the description of these repeated components. Such representations are more complex than the global representations since their specifications are intrinsically longer and usually contain far more information.

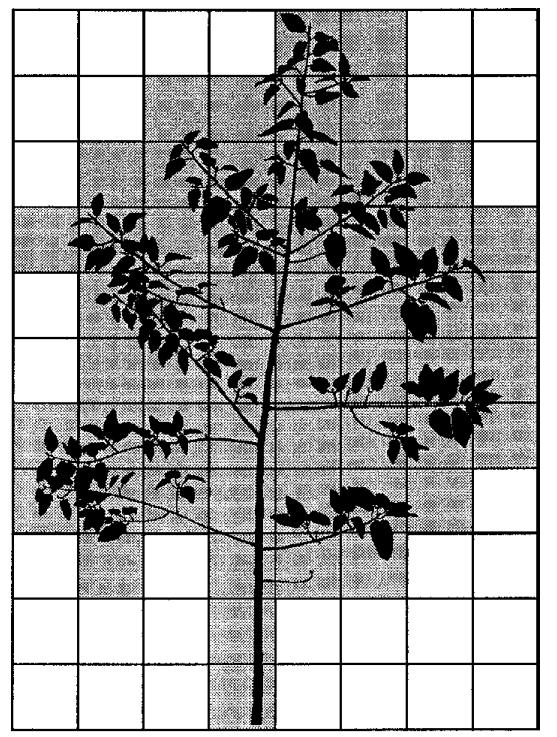

a

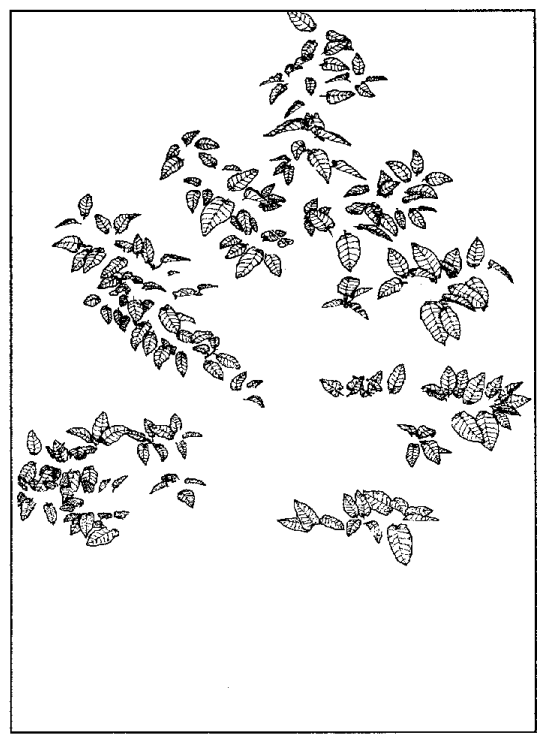

b

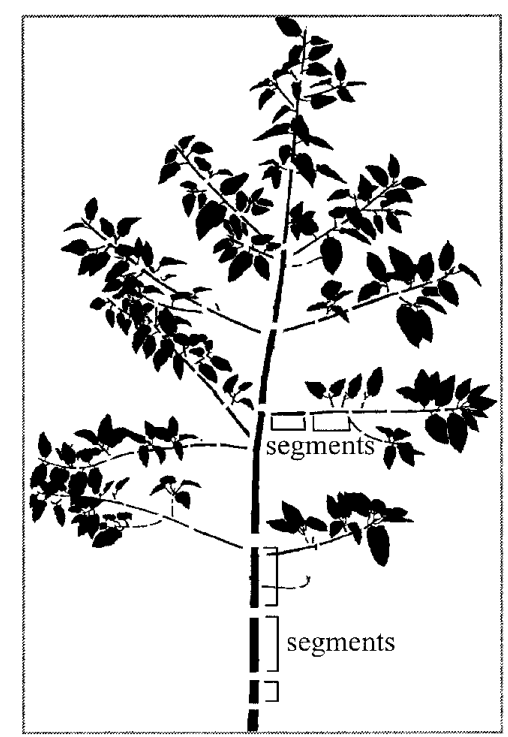

c

Figure 3. Modular representations of plant architecture a. spatial decomposition. Cells that contain vegetal elements are tagged with grey. b. organ-based decomposition of the same plant including only geometrical information about leaves. c. organ-based decomposition of the same plant including topological information. 
Two basic types of plant architecture decompositions into modules can be carried out: spatial or organ-based decompositions. In spatial decompositions, the distribution of plant modules in 3-dimensional space is approximated by tiling of the 3-dimensional space, using cells with simple and constant shape and tagging those that contain plant modules (figure 3a). Organ-based decompositions make use of plant modules and can be divided into two classes: in geometric decompositions, only the geometric aspects of the modules and their spatial positions are considered (figure $3 b$ ) whereas in topological representations, the connections between the modules are taken into account (figure $3 c$ ).

\subsection{Spatial representations}

Plant modularity can be indirectly exploited by subdividing the space in which the plant is embedded into regular cells, called voxels (figure $4 a$ ). Plant components are not directly considered in such representations. Instead, the plant is represented by the voxels containing the plant components. Biological attributes characterising these components (leaf density, optical properties, etc.) can be attached to each voxel. The size of the voxels is determined according to the application. The plant is represented in fine by a set of voxels in 3-dimensional space. Voxel-based representations have been used in the context of light interception modelling, e.g. [111] and plant growth simulation [59].

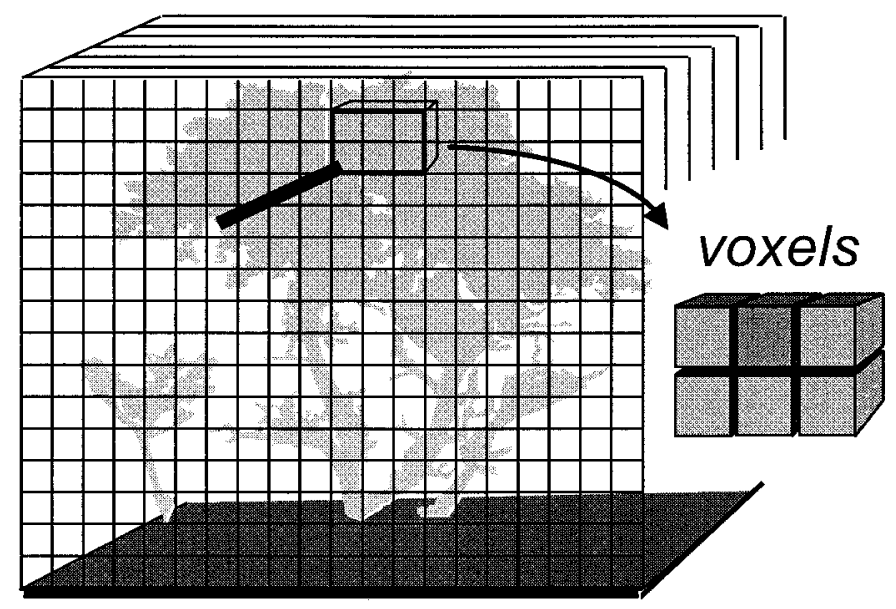

$\mathbf{a}$

\subsection{Geometric representations}

A second solution consists of decomposing plants into organs such as leaves, fruits, internodes or different types of growth units, and considering their shapes and spatial organisation. The connections between the organs are not taken into account and not all types of plant organs need to be considered. One may be interested for example in the spatial distribution of leaves (e.g. in application dealing with light interception), or roots (e.g. to identify the areas of water uptake in the soil). These types of modular representations are frequently used to obtain accurate descriptions of the plant exchange surface in applications studying the interaction between plants and their microenvironment [23, 30, 113] (figure 4b).

\subsection{Topological representations}

Topological representations are organ-based decompositions in which emphasis is placed on the connections between organs. Such representations are used in an increasing number of plant structure/function modelling fields to model either substance transfers within plants, plant growth or to measure plant architecture. Some examples of this are given below.

Several models of water fluxes in plants have been proposed based on an electrical analogy [32, 35, 51]. The plant is decomposed into components that are associated with hydraulic conductance. The water flux through a

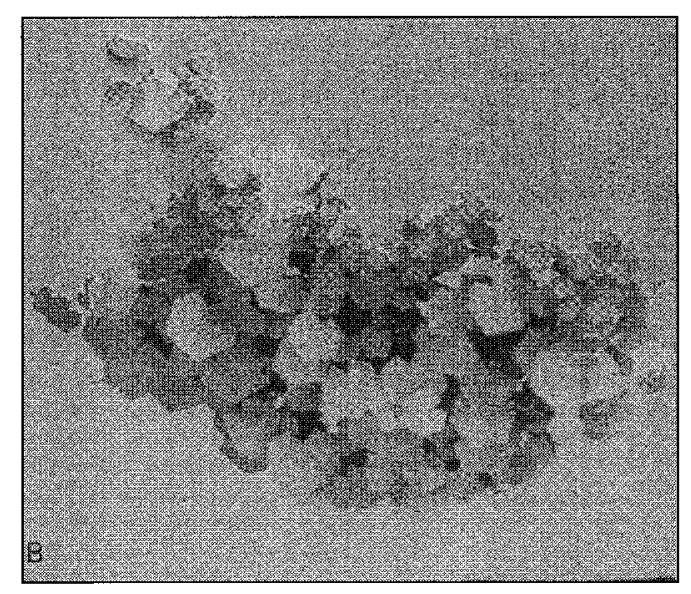

b

Figure 4. Representation of plant canopies using a. voxels with varying leaf densities. $\mathbf{b}$. a geometric decomposition of the plant into leaves (made from digitised grapevine leaves and used to assess irradiance models - from [113]). 


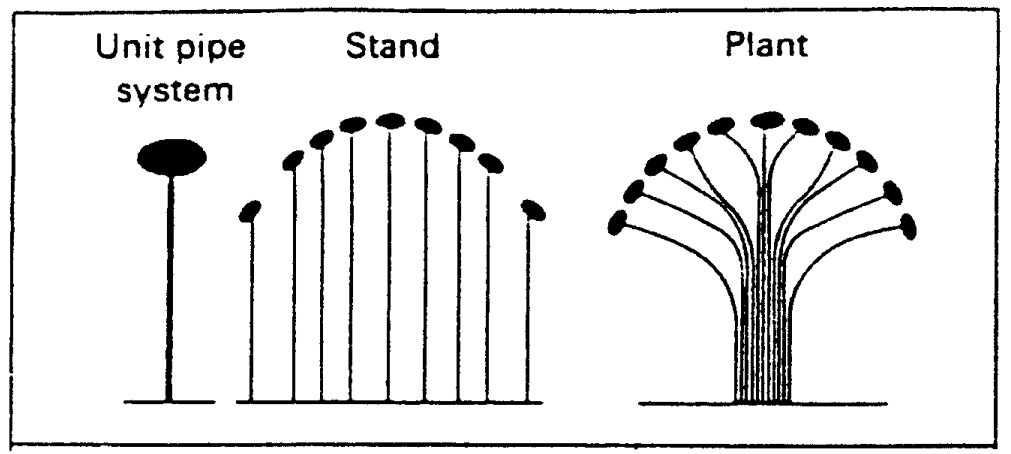

$\mathbf{a}$
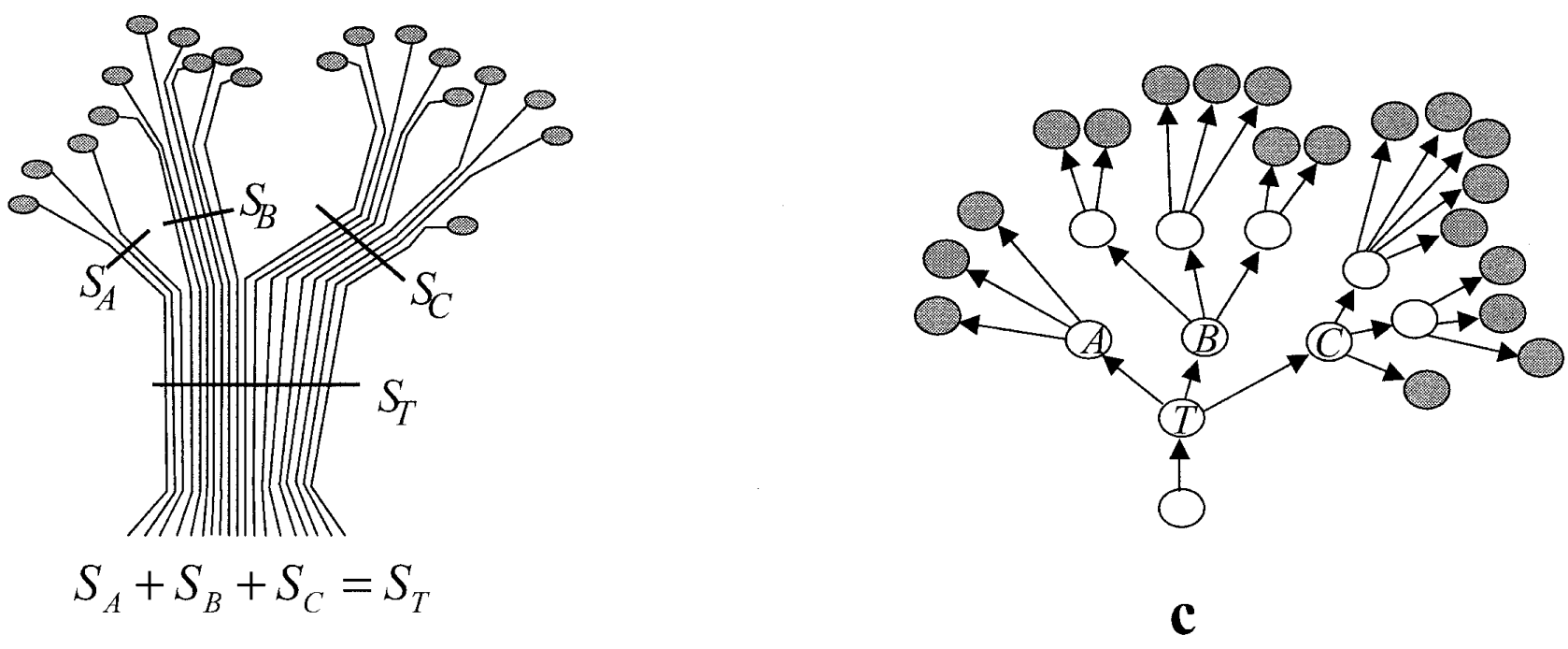

b

Figure 5. Modular description used with the pipe model theory a. Classical representation of a plant in the pipe model theory (from [107]) b. representation of a branching system with unit pipes: each segment of a tree is represented by a bundle of pipes. A Kirchhoff's current law expresses flux conservation c. Tree graph associated with the model from b. Each bundle of pipe is represented by a vertex and connection between bundles is represented by an edge.

component is assumed to be proportional to its conductance (Ohm's law). Water transfers within the plant are thus defined by a "hydraulic network" which relies on the plant topology: as in the electronic analogy, Kirchhoff's current law (see e.g. [25]) is satisfied for each component, i.e. the flux of water entering a component is equal to the sum of fluxes leaving.

Plant topology is also used to address carbon partitioning problems. In the pipe model theory, for instance, a plant is considered to be a "bundle of unit pipes" (figure $5 a$ ), each pipe bearing a unit of leaves [83, 108,
124]. Complex branching structures can be represented by connecting together unit pipes modelling plant components. The resulting structure, illustrated in figure $5 b$, defines a sapwood network for which Kirchhoff's current law is satisfied with the following significance: the number of unit pipes in a component is equal to the total number of unit pipes that compose the components connected above it [88].

Topological representations are also used in a more abstract manner to simulate the propagation of substances through plant components. A first problem here consists 
of simulating the competition between branches for limiting resources through the plant component network [19, 35]. A second problem lies in the study of signal propagation through plant topology. Such modelling may be used to explain time of flowering in branching inflorescences for example [68].

As computers have become increasingly powerful, plant growth simulation programs have made extensive use of the topological representation of plant architecture to obtain realistic 3-dimensional rendering of computed plant architectures, e.g. [34, 39, 45, 46, 48, 97, 127]. This use of 3-dimensional representations was initiated by Honda [65] who demonstrated that complex crown shapes could be obtained using a limited number of geometric parameters and that plant architecture is very sensitive to changes in these parameters.

The above list of applications using a topological representation of plant architecture is naturally not

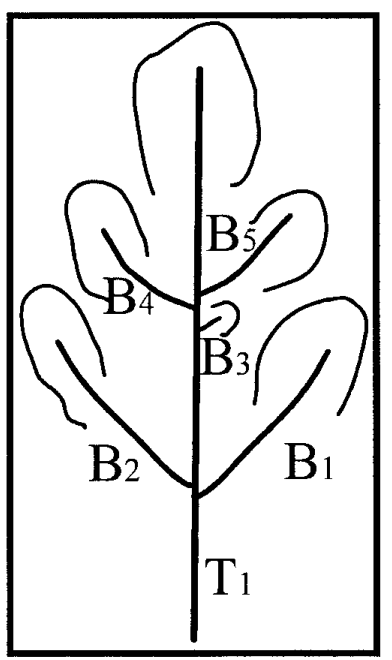

$\mathbf{a}$

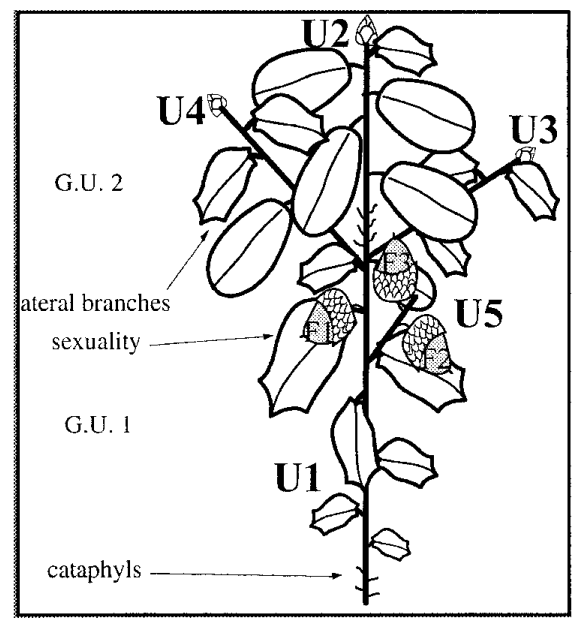

c

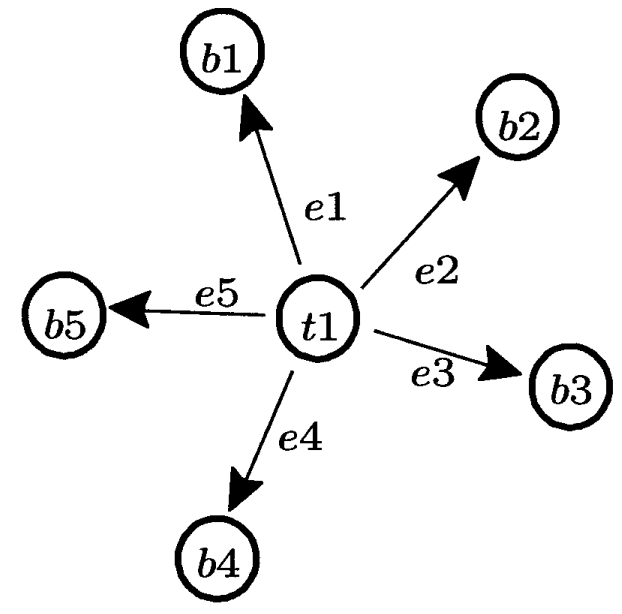

b

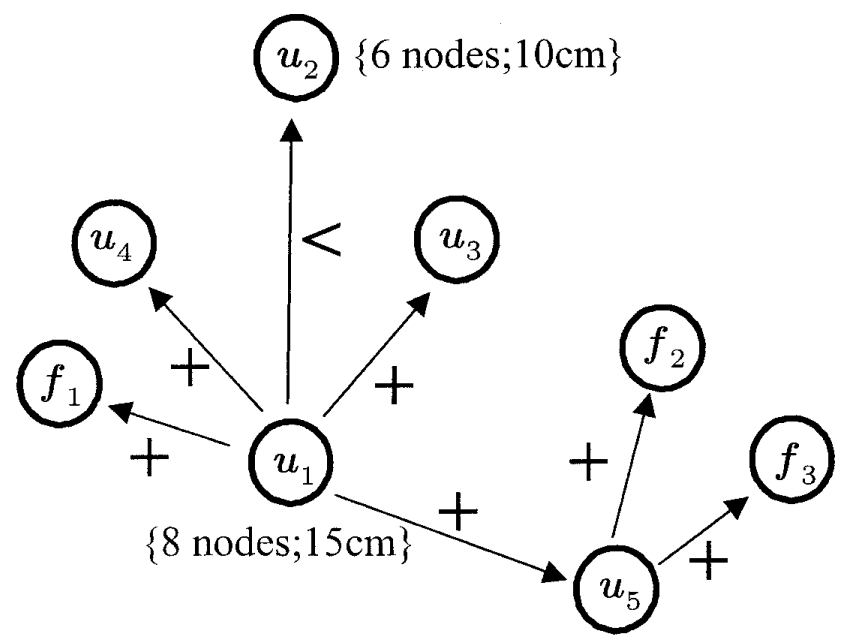

d

Figure 6. a. A tree - considered as a set of branches - and b. the tree graph representation of its branch topology c. an oak tree branching system described in terms of growth-units and $\mathbf{d}$. its corresponding augmented tree graph (from [52]). 
exhaustive. However, it is intended to reflect the wide variety of fields in which plant topology has been adopted to refine plant representations. All these plant representations have a common underlying structure, namely that of a tree graph.

\subsubsection{Tree graphs}

Let us consider the set of components resulting from decomposition of a plant into modules. The network made by these connected components can be represented by a binary relation defined over the set of plant components, i.e. a graph. Because of the special nature of plant growth, graphs representing plant topology are of a particular type [52], known as tree graphs (for an introduction to graph theory see e.g. [57, 89]). Figures $6 a, b$ illustrates a tree graph in which each branch is represented by a vertex and connections between branches are represented by edges between vertices. Two types of connections can be distinguished to mark the hierarchical organisation of components in plants. A < (precedes) denotes the connection between two components that have been created by the same apical meristem. A + (bears) denotes the connection between two components that have been created by different apical meristems. Additional information can be associated with plant organs in topological representations by adding features to the corresponding vertices in the tree graph. This infor- mation may correspond to the spatial position of an organ in space, its geometry, or any other characteristic of the organ. The resulting representation is called an augmented tree graph (figures $6 c, d$ ).

A slightly different way of representing plant modularity by a graph, called axial trees, has been proposed by Prusinkiewicz and Lindenmayer [96] in the context of plant growth simulation with L-systems. In axial trees, plants are described as tree graphs where vertices represent connecting points between plant components and edges represent the components themselves. This convention mirrors that presented above (vertices in one representation are edges in the second and vice versa), and is equivalent to augmented tree graphs (figures $7 a, b$ ).

\subsubsection{Computational representation of tree graphs}

In all the preceding examples, plant topology can be modelled by a tree graph whose vertices have different types of attributes: conductance, water flux, number of unit pipes, geometry, etc. For example, in the case of unit pipes, the pipe representation of a tree (figure $5 b$ ) can be alternatively represented as a tree graph (figure $5 c$ ), which emphasises the topology of the tree and defines a representation independent of the modelling context (here, independent of the pipes). However, whereas tree graphs are very general means of representing plant

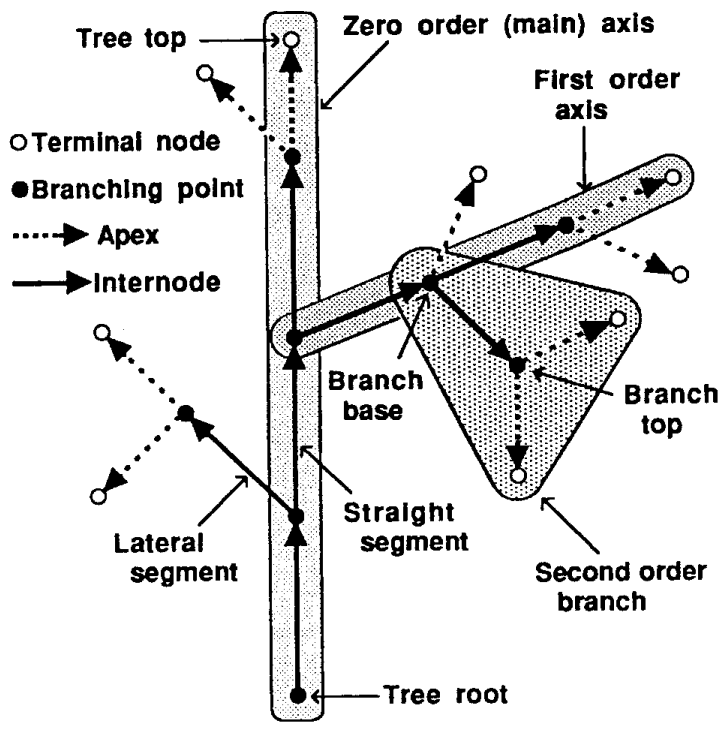

$\mathbf{a}$

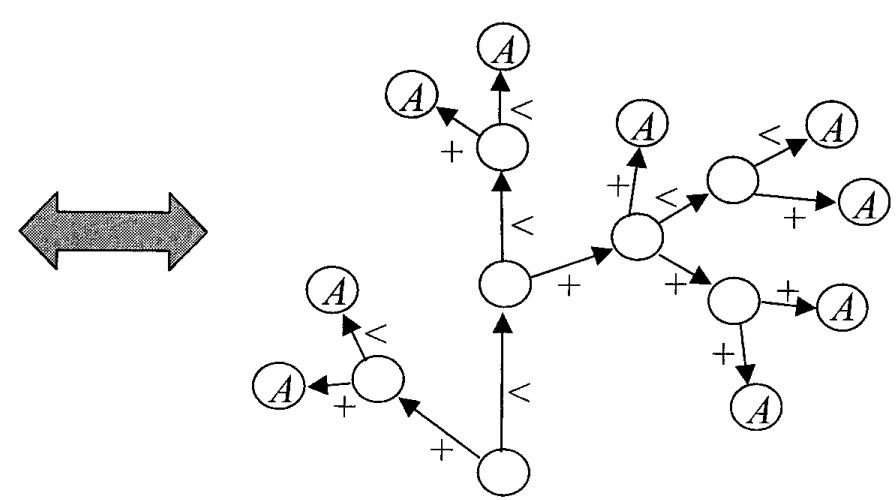

b

Figure 7. Equivalence between an axial tree (from [96]) a. and an augmented tree graph b. 


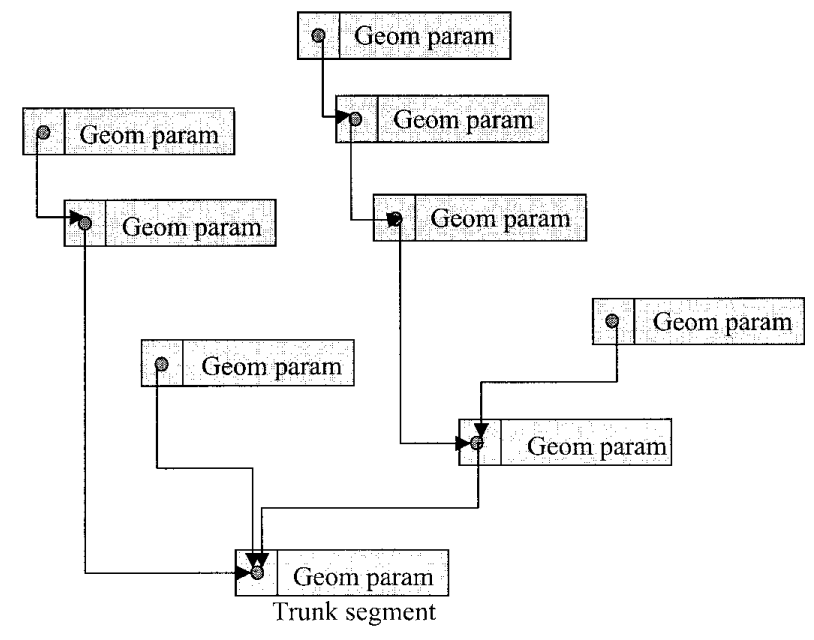

Figure 8. Representation of plant topology by chained lists of records.

modularity, there is no universal method to computationally represent them. By contrast, various methods with specific computational properties may be considered $[2,57,118]$. A brief description of the major implementations of tree graphs is given below.

The most commonly-used manner to implement a tree graph is to use a chained list of records (figure 8). Each vertex representing a plant component is associated with a record containing a pointer to the record representing its parent vertex. Since each vertex in a tree graph has only one parent at most, a single pointer is needed for each record. In addition, each record may store further information associated with the corresponding vertex (such as position, geometry, light environment, etc.). This solution is flexible: new components can easily be added or removed and the use of memory to describe the topology is reasonably efficient since the storage of a graph containing $N$ vertices takes a space proportional to $N$, though this is not optimal. Also, the search for the parent vertex of a vertex is very efficient and can be made in constant time. Variations can be made in such implementations to reduce either access time or storage space, see e.g. [2, 57];

Tree graphs can also be represented as matrices. Here, the vertices and the edges of a tree graph are indexed. A matrix $M$ is considered whose rows and columns are respectively associated with the vertex and edge indexes. This matrix is called the incidence matrix of the tree graph (figure 9). If an edge $e$ is incident to a vertex $v$ and directed away from vertex $v$, then cell $(v, e)$ contains 1 . If an edge $e$ is incident at a vertex $v$ and directed toward $v$, then cell $(v, e)$ contains -1 . Otherwise cell $(v, e)$ contains 0 . A matrix representation of graphs can be used to write equations to describe the flows on these graphs in a synthetic algebraic manner. For instance, Kirchhoff's current law can be summarised using the above incidence matrix by the following equation:

$$
M I=0
$$

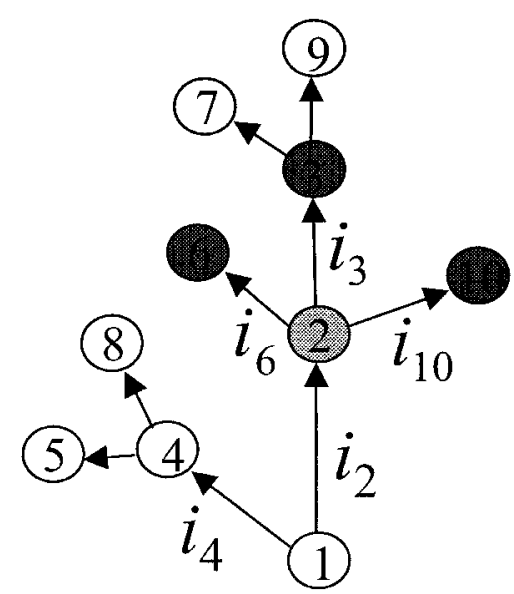

$\mathbf{a}$

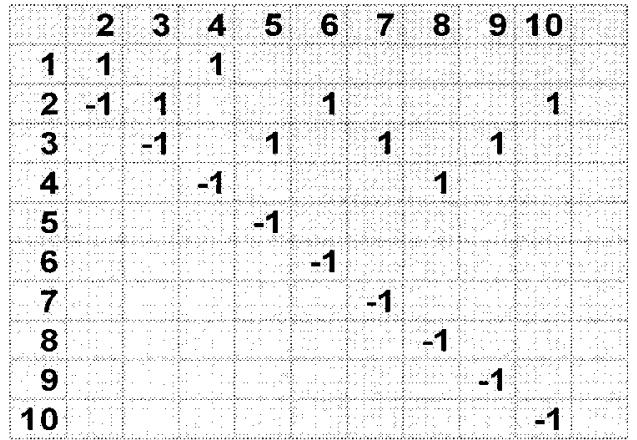

b

Figure 9. Representation of plant topology by a matrix. a. a tree graph with fluxes going through its nodes (flux $i_{n}$ passes through node $n)$. b. Corresponding incidence matrix: lines correspond to vertices and columns correspond to edges (see text for detailed explanations). 
where $I$ is the column vector composed of the value of the flux entering each vertex in the graph. However, matrix representations of tree graphs have one major drawback. Because each vertex in a tree graph is only connected to a few other vertices, the resulting matrix is sparse, i.e. a matrix with many null cells (figure $9 b$ ). When describing a plant with a large number of components, this causes storage problems (the storage of a graph with $N$ vertices and $M$ edges takes a space proportional to $N \times M$. Since in a tree, $M=N-1$, the space is of the order of magnitude of $N^{2}$ ). However, techniques have been developed in applied mathematics for efficient computation using sparse matrices, e.g. [90]. Fourcaud for instance [49, 50], used a matrix representation and a specific sparse matrix decomposition scheme to apply efficiently a finite element method for modelling the mechanical constraints within the branches of a growing tree.

Tree graphs can also be represented by strings of characters. This is a common scheme in computer science (a computer program for instance can be thought of as a string of characters representing a (tree graph) hierarchy of expressions). This has proved particularly useful in plant models based on L-systems (see [92] for a review). In this case, vertices are represented by letters. To represent an axis, letters associated with vertices representing successive components in the axis are concatenated one after the other. A branch is thus represented by a string of

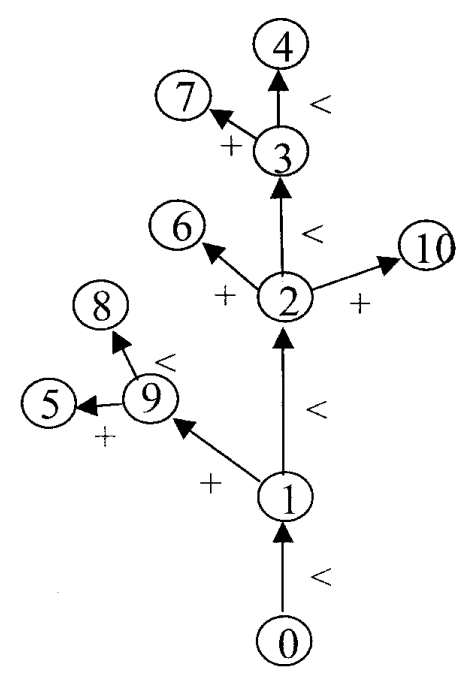

\section{1 [9 [5] 8] 2 [6] [10] 3 [7] 4}

Figure 10. String representing a tree graph. Such strings are used to encode plant architectures. characters. Axillary branches can be added by inserting their string representation into the previous string using a bracket notation (figure 10). A whole branching system is thus defined by nested strings of characters. String representations are concise and provide optimal topology representation in terms of storage efficiency (one vertex $=$ one letter and no pointers are used). However, seeking for the parent of a component may take a time proportional to $n, n$ being the length of the string up to the letter associated with this component. Thus, computation that makes use of the topological connections of a component, for all plant components (e.g. propagating substances through plant topology), may take a time proportional to $N^{2}, N$ being the number of plant components.

All these implementations of tree graphs can actually represent a plant architecture within a computer system. As discussed above, they have different computational properties, but they can all be used in plant growth simulation programs: a growing architecture will be represented either by a chained list with an number of records increasing with time, by a matrix with an increasing number of rows and columns, or by a string with an increasing length.

\subsection{Encoding plant architecture}

It is sometimes necessary to represent plant architecture topology in a legible manner. This can be used for example to describe the topology of a plant observed in the field or to transfer plant architecture data between two computer programs. Such encoding schemes rely on the representation of tree graphs as strings of characters.

Several such encoding strategies have been described in the literature. Certain strategies have been developed for specific plant species, e.g. cotton [126] and soybean [71] (figure 11a). Others are more generic and do not depend on plant species [62, 101], (figures 11b,c). However, these approaches focus on a particular plant modularity, most frequently at the internode or growth unit levels. These schemes enable the user to describe the topology of plant individuals. In a slightly different perspective, Robinson [102] proposed an encoding scheme to formalise the description of architectural models [61], (figure 12).

\subsection{Discussion}

To conclude this section, let us summarise the advantages and drawbacks of using modular representations in plant modelling. 


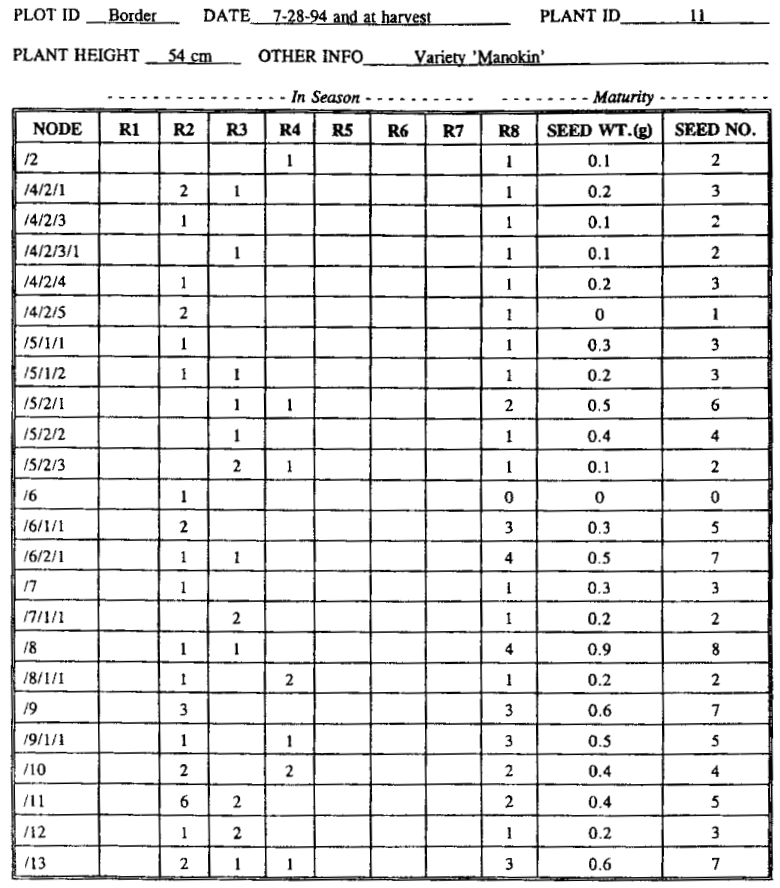

a
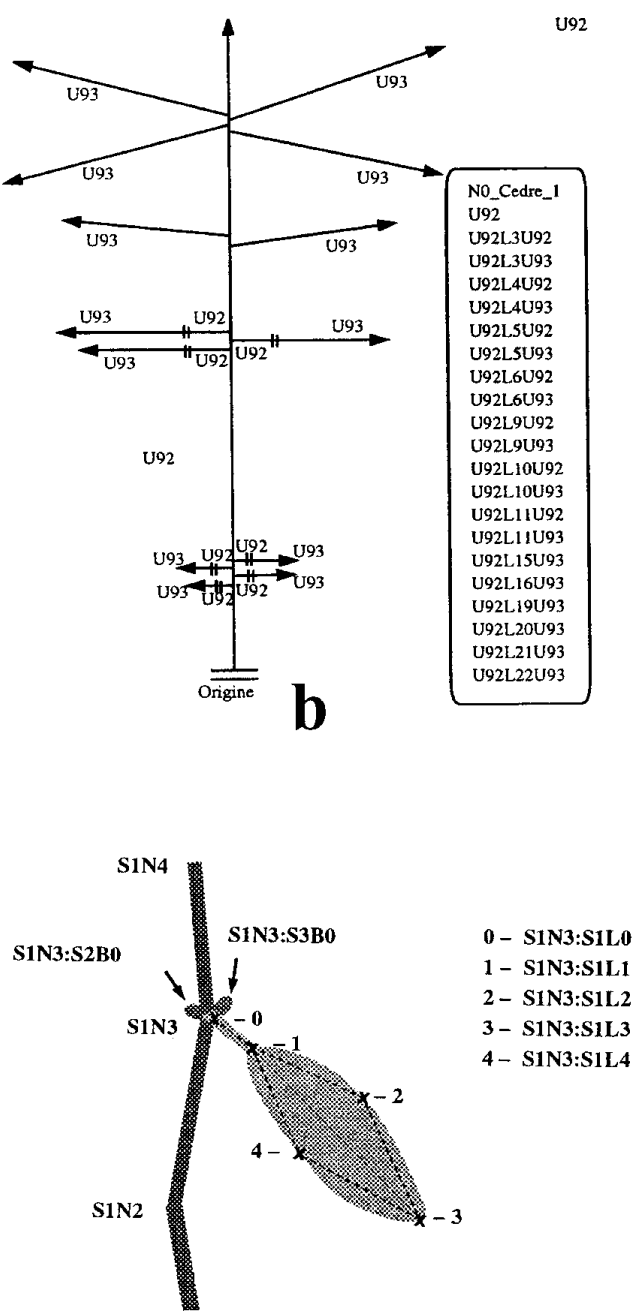

C

Figure 11. Different encoding schemes used to record plant topology in the field. Encoding strategies have been designed for specific plants a. (soybean plant from [71]) or for general plants b. (from [101] ) and c. (from [62]).

A basic advantage of using modular representations is directly inherited from the classical analytical method of tackling complex phenomena: the phenomenon (here the plant) is decomposed into small components that can be treated more simply. The phenomenon is then assumed to be adequately described as the union of these basic component models. The hope here is that this will lead to greater understanding and more accurate modelling of biological phenomena than use of global representations.

However, this approach has some drawbacks. First, the use of a modular rather than global representation greatly increases the size of the plant description. Special techniques must therefore be designed to control the overall amount of data and computation, e.g. [38]. Second, since the level at which the plant is described is finer, modellers frequently attempt to tackle new phenomena that appear at this more detailed scale. For example, modelling tree crown geometry at the level of branches requires that the model integrates some description of the branch distribution along the trunk. This information need not be taken into account when using a global model of tree crown geometry (see Sect. 2). Similarly, models that use an electrical analogy for substance propagation within the tree structure contain a number of parameters proportional to the number of plant components. Again, a coarse model describing substance transfer at the tree scale would be far 


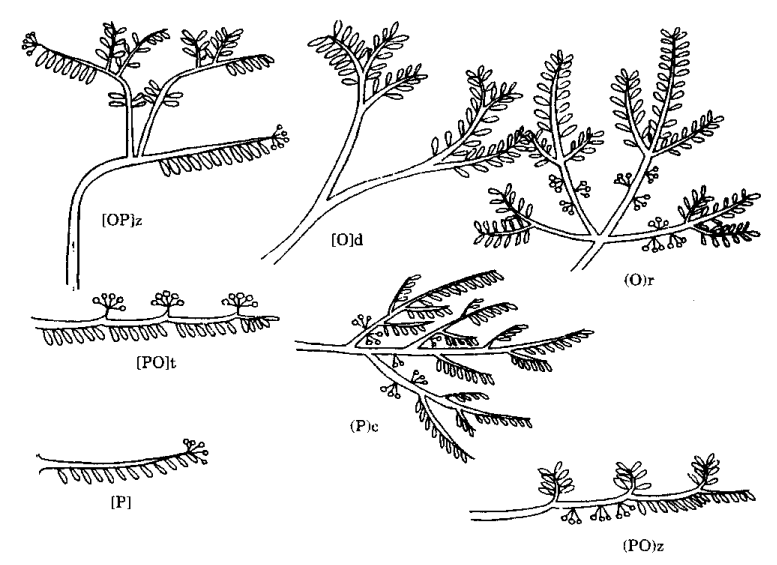

$\mathbf{a}$

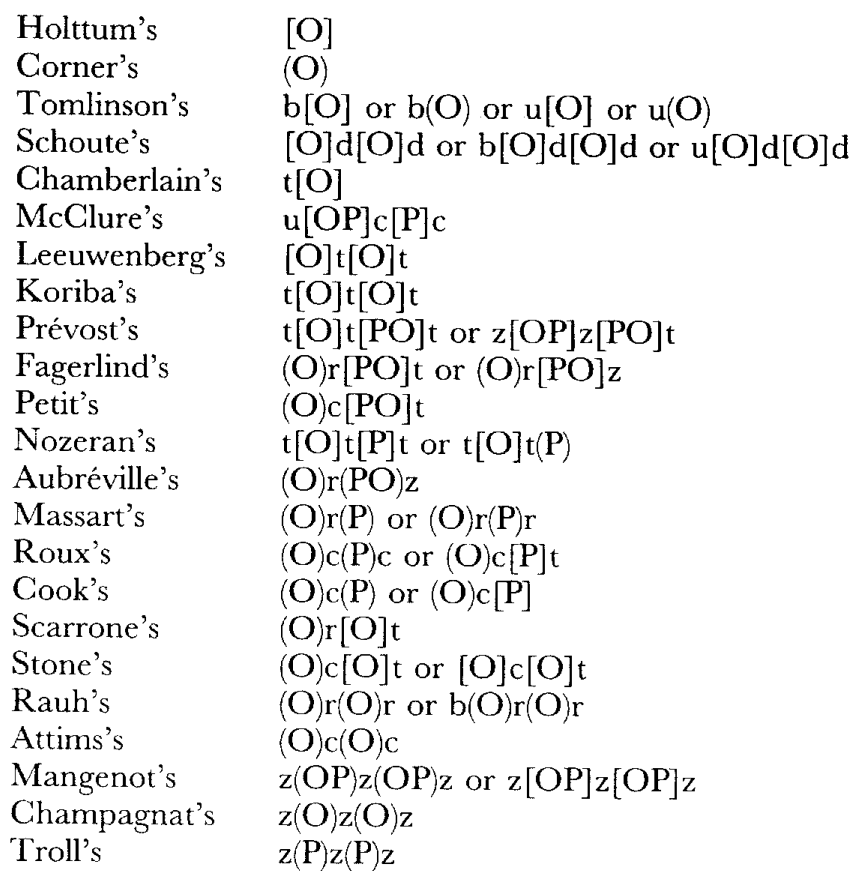

b

Figure 12. Encoding scheme for architectural models (from [102]). O stands for orthotropic, $P$ for Plagiotropic, $t$ for terminal, $d$ for dichotomous, $[\mathrm{O}]$ means determinate unit, $(\mathrm{O})$ indeterminate, etc.

more parsimonious. Therefore, more detailed descriptions frequently lead to an increase in the size of the model, i.e. the use of a larger number of parameters. Finally, an additional shortcoming of modular representations results from their dependence on the a priori choice of a level of description. A particular type of module is chosen to represent a plant and this is frequently determined by the application aims and constraints. Classical modules are branching systems, axes, different types of growth-units and internodes. The plant is then decomposed into components corresponding to the repetition of this module in the plant architecture. The assumption (made explicitly or not) is that the chosen level of description corresponds to the optimal level at which the studied phenomenon can be decomposed into pieces and analysed. This suffers from a lack of flexibility: first, facts from different levels of description may be related to the observation of a phenomenon at a given scale. Second, in order to account for this possibility, modular representations must be modified to support information from other scales. Systematic approaches to the integration of phenomena occurring at different levels of detail in plant architectures have resulted in multiscale representations.

\section{MULTISCALE REPRESENTATIONS}

The first informal multiscale descriptions were used in architectural analysis where accuracy in architectural model description is achieved using details from many different scales. Figure 13 illustrates such multiscale descriptions [85]. This picture contains details at forest, tree, branching system, axis and inter-branch segment scales. The need to formalise such multiscale descriptions of plant architectures was recently advocated by several authors $[56,88,100]$.

In parallel to the work conducted in architectural analysis, preliminary attempts were made to quantify multiscale aspects of plant architecture in the 1980's, inspired by a new emerging field of mathematics: fractals $[78,79]$. Mathematicians, e.g. [78, 79], are often reluctant to give formal definitions of fractals. However, a fractal object has in general two important properties: it is characterised by irregularities at every scale and has a homogeneous mass distribution, e.g. [122]. If the distribution is heterogeneous, one speaks of multifractal objects $[4,58$, 78]. Intuitively the fractal (or multifractal) character of an 


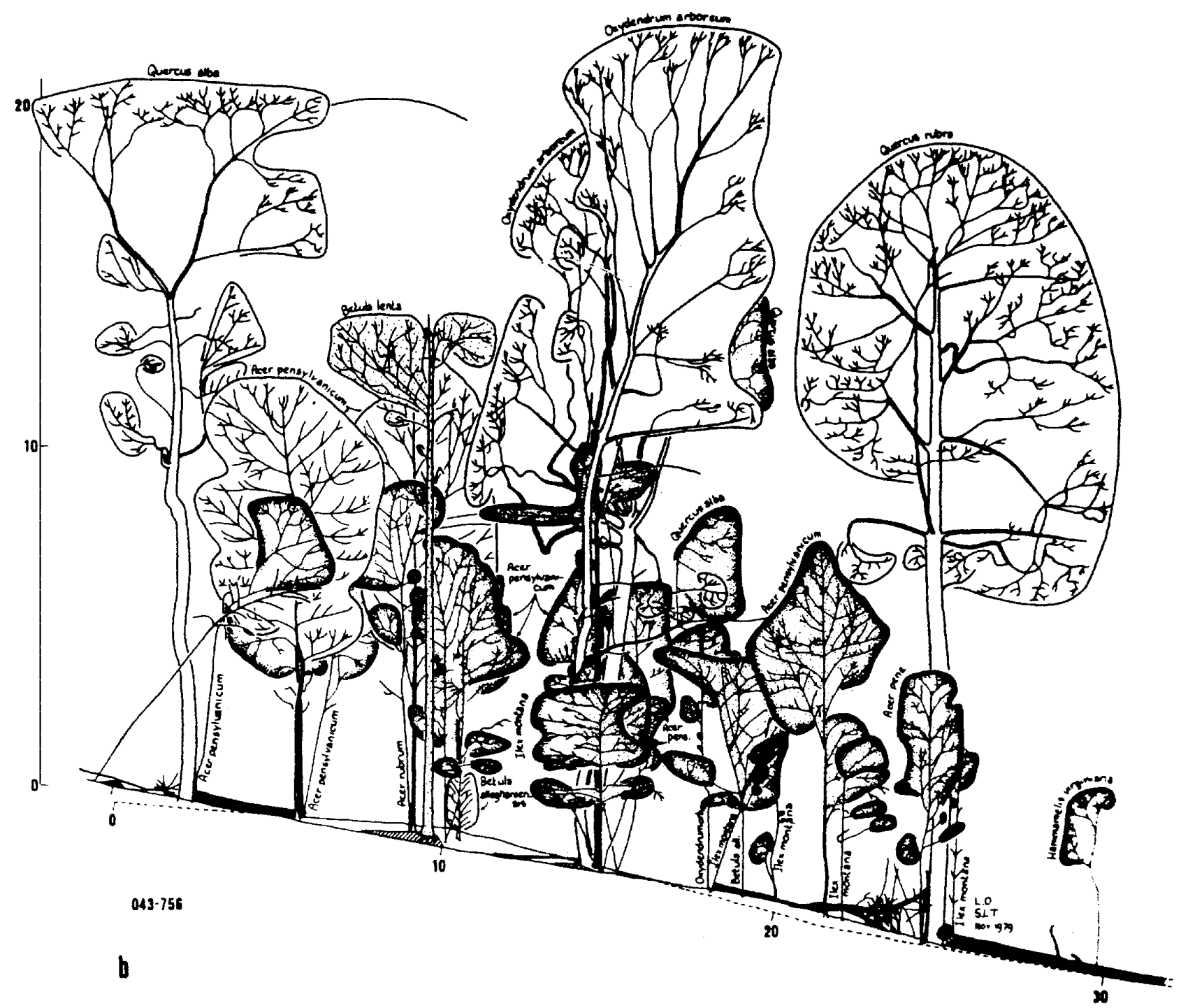

Figure 13. Architectural description of a forest showing various levels of detail (from [85]).

object is related to the fact that new details appear when zooming in on the object. If new details appear at every scale, the "length" (or surface or volume) of ideal fractal objects must be infinite (e.g. [82]). A case of particular importance occurs if fine grain details are similar to coarse grain details, then the object is said to be self-similar (figure 14a).

In the strict sense, branching systems in plants are not fractal objects. They do have complex structures with more or less obvious self-similarity $[33,96]$, but they do not have infinite length: actually, real plants have a frac- tal-like aspect only within a limited range of scales (figure 14b). This property can be brought to light in every tree-like structure by considering that such structures can be approximated at scale $i$ by their branches up to order $i$ and that zooming in on these structures reveals new details corresponding to order $i+1$ branches. In this sense, every branching structure exhibits fractal behaviour, at least within a certain range of scales (figures $14 a, b$ ).

As illustrated by this remark, modelling plants in the context of fractals has effects on two major aspects of the modelling strategy. The first concerns the simulation of 

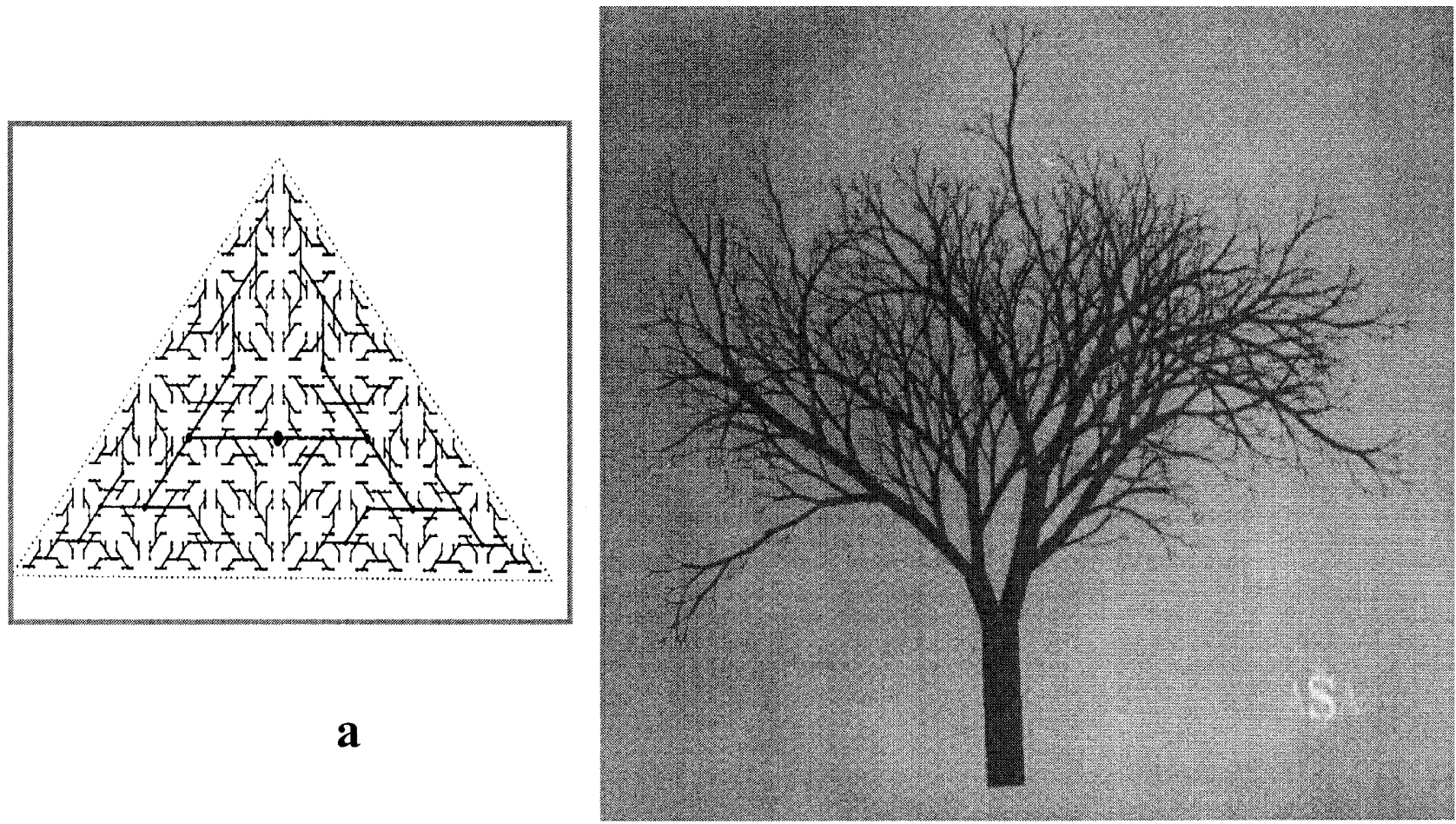

Figure 14. a. Self-similar formal tree resulting from a fractal process. The theoretical output is a fractal object, i.e. it has details at every scale and has an infinite length (from [82]) b. Virtual and realistic tree obtained from a fractal process (e.g. [125], Photo by Viennot).

plant growth: similarly to fractal object generation, plant growth can be simulated using a recursive process $[86$, $94,114]$. The second, central to our subject, concerns the nature of the plant structure itself: similarly to fractal objects, the plant structure contains details at different scales of description.

For plants as for fractals, we may define a notion of scale from the process of tiling an object using some chosen measurement unit $[58,78,122]$. A scale (of description) is defined by the choice of a unit used to tile up the object (here a plant). The finer the unit, the finer the description (i.e. the higher the scale of description). In this sense, we can speak of the description of a plant at the annual shoot scale (for instance), meaning that the plant has been decomposed and described (tiled) in terms of its annual shoots.

The architectural or fractal approach (or sometimes both) have been at the origin of attempts to represent mul- tiscale phenomena within tree crowns since the 1980's. Both result in different types of multiscale representations of plant architecture that are reviewed hereafter. As already seen for modular representations, these approaches can be divided into three categories depending on the type of multiscale decomposition, i.e. either spatial, geometric or topological.

\subsection{Multiscale spatial representations}

The first type of representation consists of decomposing the Euclidean space into voxels of varying sizes. The size of any voxel is adapted to local shape irregularity: the more irregular the shape, the finer the voxels. Such hierarchical data structures have been used for many years in engineering to deal with partial differential equations using finite or discrete element methods on domains with complex shapes (e.g. [98]). A similar tiling is also used to 


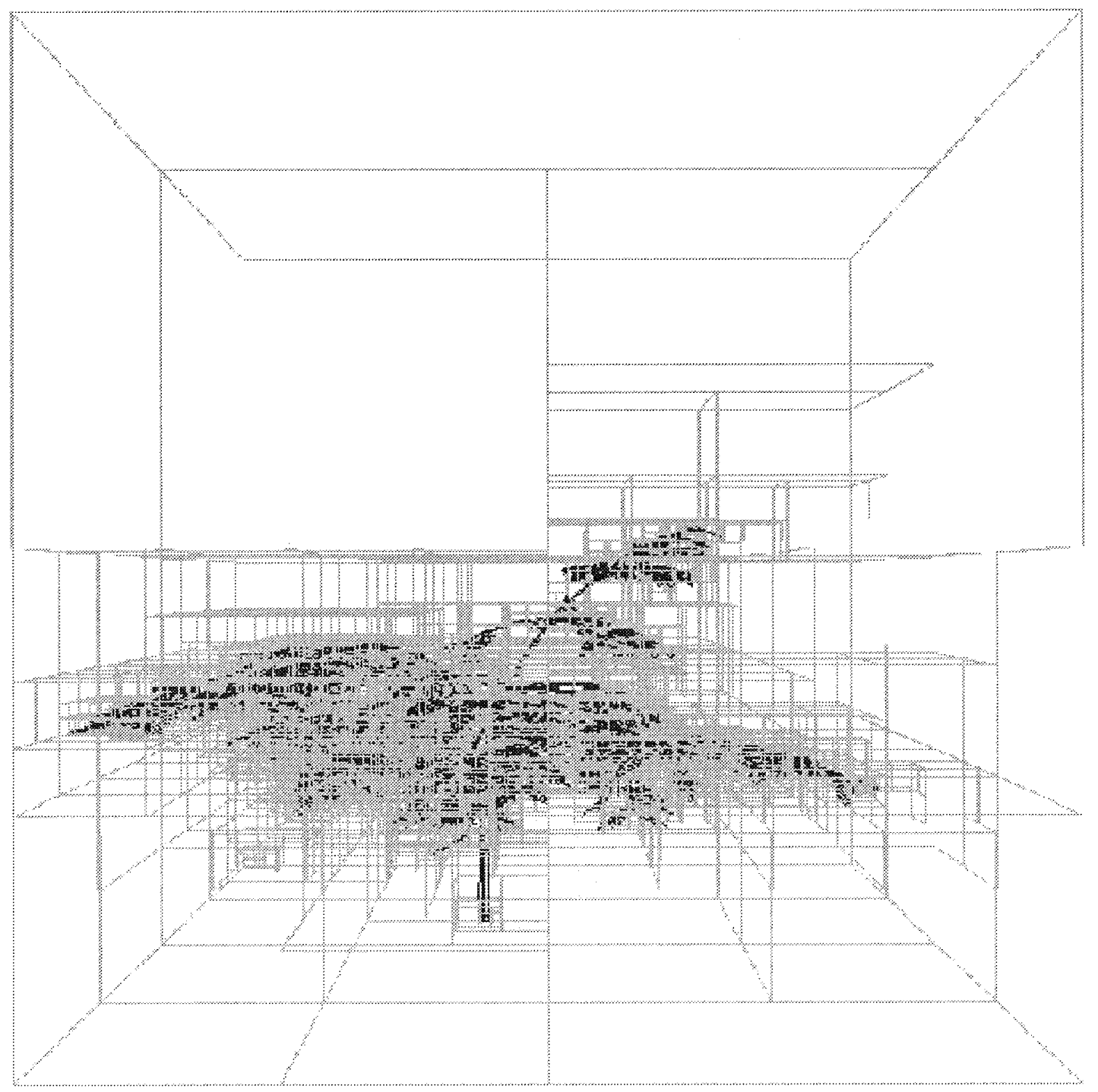

Figure 15. Multiscale voxel-space: the plant architecture is approximated by voxels whose sizes are locally adapted to the irregularity of the plant geometry (From [109]).

compute the Hausdorff dimension of a fractal object (e.g. [42]). Recently, Sillion et al. adapted a hierarchical approach of radiosity methods to model the energy exchanges between vegetation elements [28, 109]. To increase the efficiency of radiosity methods, plant architecture is decomposed into voxels of different sizes and radiosity properties corresponding to the actual vegetation elements they contain. An octree technique is used to locally adapt the size of the voxels to the level of detail of the plant components (figure 15).

\subsection{Multiscale geometric representations}

A second type of representation consists of decomposing the global shape into smaller shapes, and so on until the desired level of accuracy is obtained. Zeide [130, 131] used such multiscale geometric decompositions in forestry applications to characterise the complex shape of forest-tree crowns, assumed to have a fractal nature, by comparing the surface of the geometric representations of trees at different scales, see "the two surface method" 
[129]. Multiscale geometric representations have recently been used in computer graphics to model the complex geometry of biological organs in a hierarchical manner [7]. These methods are currently being investigated to introduce multiscale geometric representations of tree crowns to model radiative transfers in canopies.

\subsection{Multiscale topological representations}

The fractal aspect of plant architectures has lead several researchers to design plant growth simulation systems using fractal concepts such as self-similarity, scale, recursion, dimension, etc. [24, 86, 94, 114, 125], (e.g. figure $14 \mathrm{~b}$ ). In these approaches, the plant representation is not fundamentally different from that used in modular approaches. The fractal aspect of these approaches lies in the recursive process that generates a self-similar structure in a few steps $[9,92]$. Like for modular approaches, the plant topology is represented by a tree graph, using a single "unit" of description (for instance internodes). Increasing levels of detail are expressed by additional branching structures, e.g. by increasing branching orders (figure 16).

In the 1990's, other types of multiscale plant representations were introduced, making explicit the existence of entities at different levels of detail. Relying on architectural analysis concepts, AMAP simulation software uses a layered data structure where different types of plant component are represented at different scales: internode,

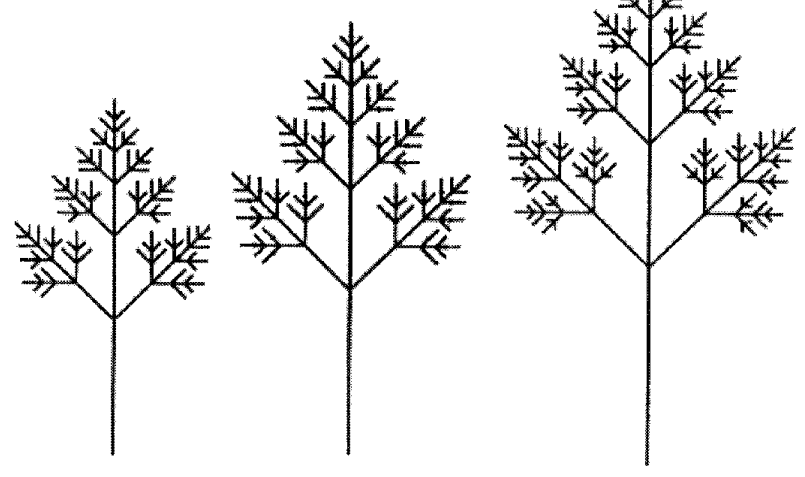

Figure 16. Developmental sequence of a branching system modelled using a tD0L-system (from [96]). New details correspond to new branching orders.

growth unit, axis and reiteration [17, 66] (figure 17). This data structure is used in plant growth simulation to adapt meristem production to the nature (age, order and physiological state) of their embedding growth unit and axis. A similar plant representation is used in INCA [74] where the paradigm of expert systems is used to model the plant growth process. This growth is governed by a set of rules (written in Prolog) expressing the conditions of meristem growth and differentiation as a function of the physiological state of the plant components at different scales. In
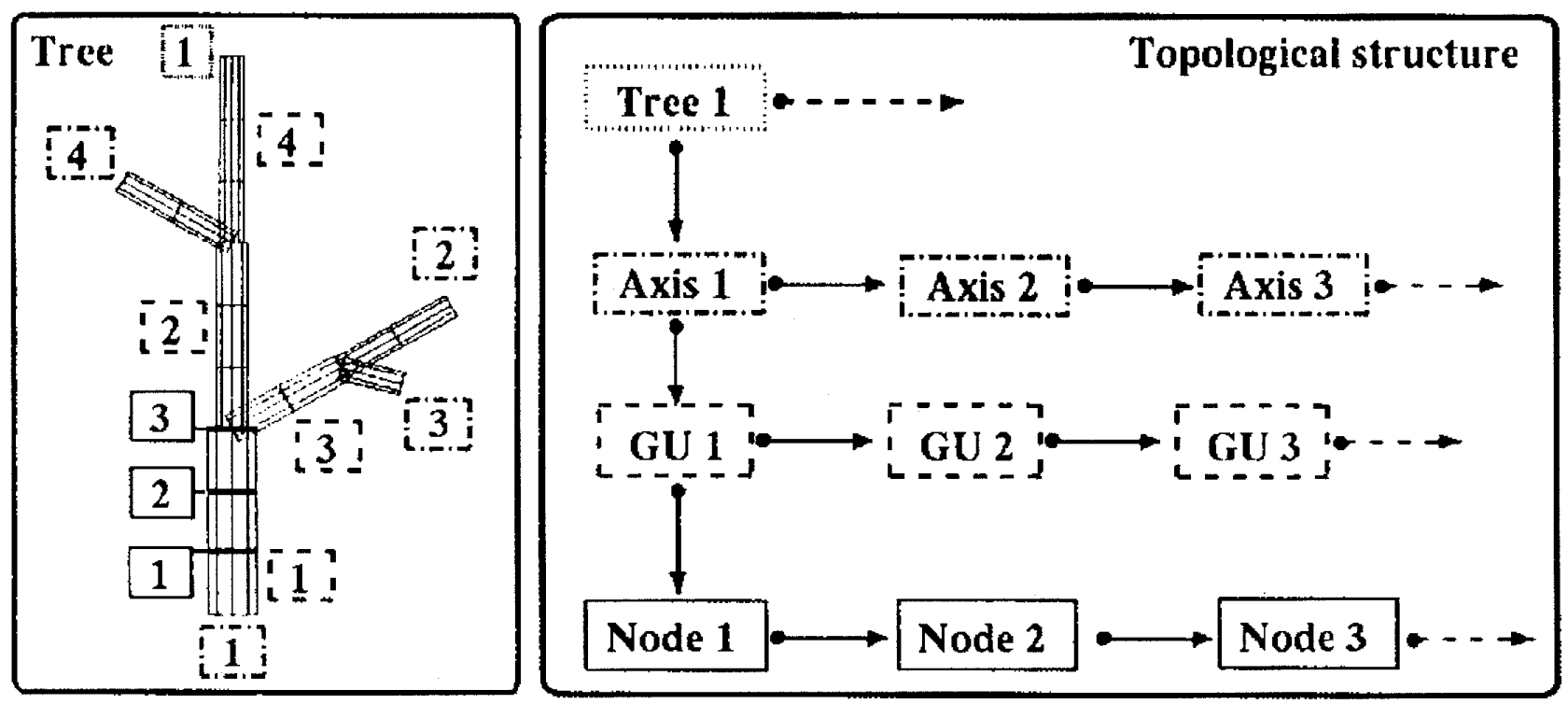

Figure 17. Organisation of records representing plant architecture in AMAPpara software (from [18]). 
turn, the multiscale data structure representing plant architecture is updated with new physiological values and with new components at different scales.

Multiscale plant models can also be found in objectoriented approaches. Here, the intention is to describe the structural-functional properties and the relationships between the components as closely to reality as possible. The emphasis is therefore on the design of objects that represent plant components. In object-oriented approaches, objects are more than simple data structures in the sense that objects also define the manner in which the data they contain may be accessed and used (e.g. [64]). Salminen et al. [105] used an object-oriented approach to specify the nature of plant components at different scales and determine their structural and functional connections (figure 18a). With such a specification, the simulation program builds up a plant representation which contains components at different levels of detail, i.e. a multiscale data structure (figure 18b). Here, it is expected that emergent properties (such as plant morphology, trunk volume, crown aspect, etc.) will derive from a local but detailed modelling of the interaction between plant components.

These approaches were designed to account for interactions occurring between components at different scales during plant growth simulations and did not place much emphasis on the multiscale representation of the plant itself. Godin and Caraglio [52] formalised the notion of growing multiscale structures and studied their mathematical properties. The resulting plant architecture representation model is called a multiscale tree graph (MTG) and is the multiscale counterpart of the tree graph model described in the previous section. Following the definition of the notion of scale used in fractal geometry (see above), a scale in a MTG is associated with a unit of decomposition. In figure 19 the plant has been decomposed at three different scales corresponding to three units of decomposition, axis, growth units and internode. At each scale, the plant structure is represented by a tree graph. All these tree graphs are integrated within a MTG by making explicit the decomposition relationships between the components.
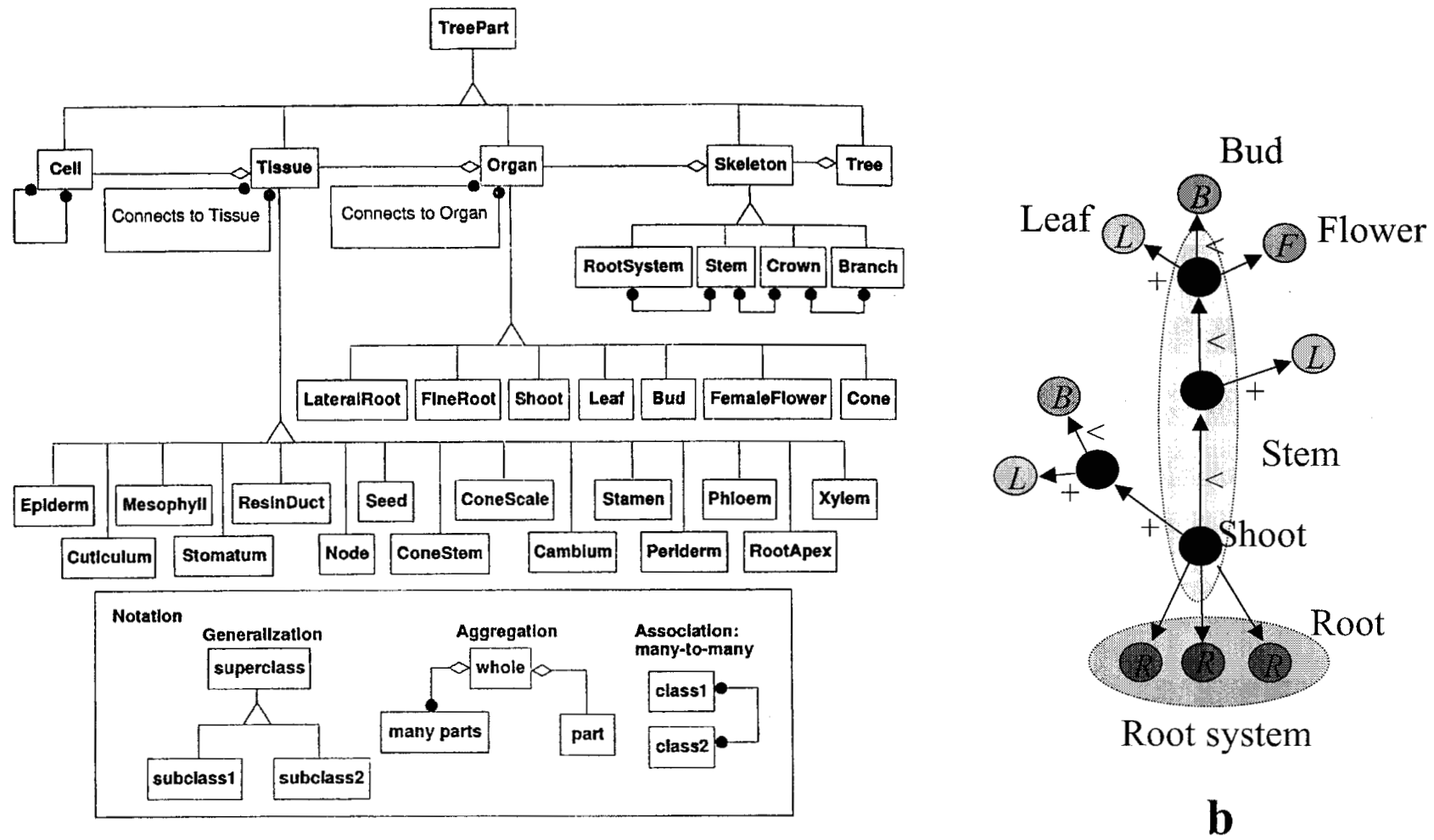

$\mathbf{a}$

Figure 18. Object oriented approach. a. Formal specification of the functions and structural relationships between plant organs (from [105]) b. Plant architecture representation produced by a program using such an object-oriented specification. The different types of grey levels represent the different types of objects as defined in a. 


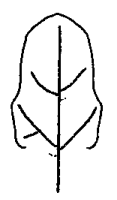

\section{Axes}

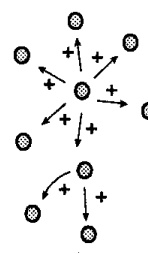

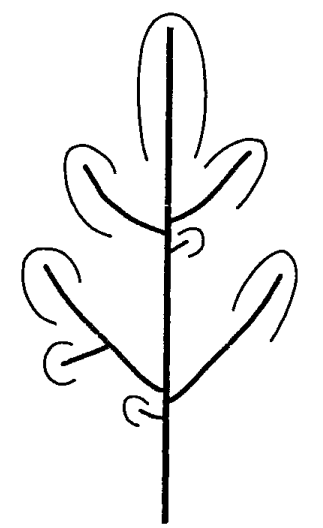

Growth units
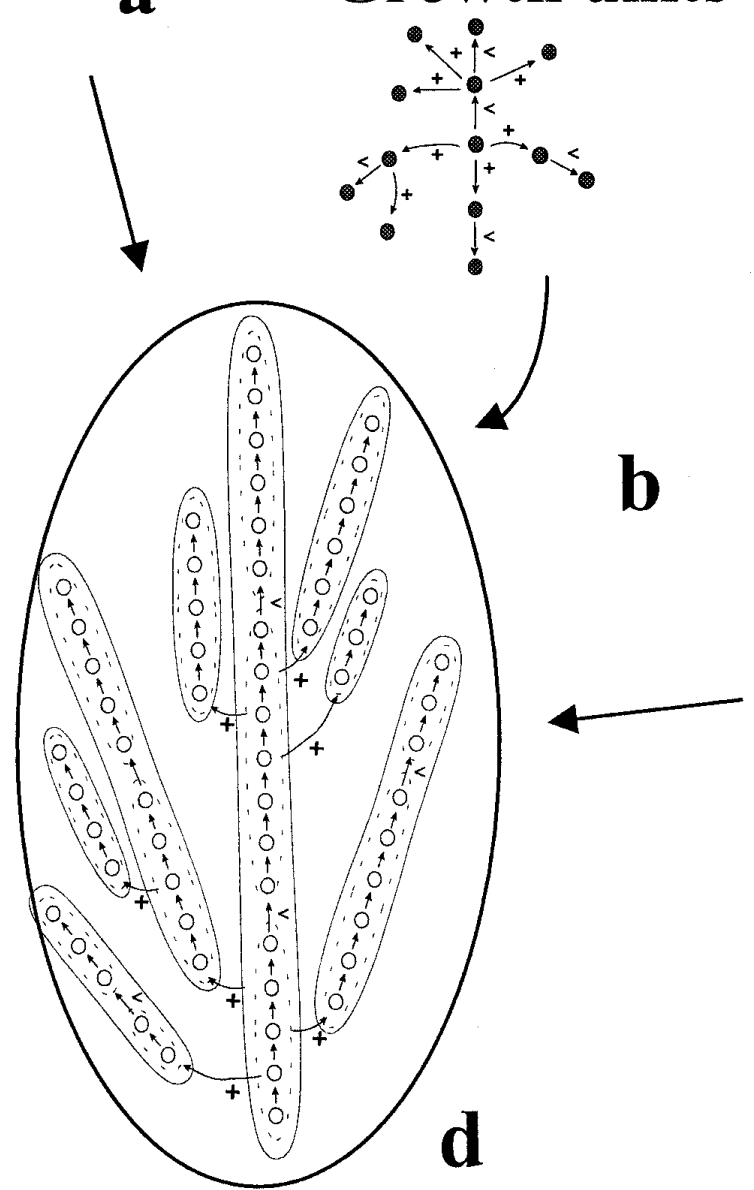

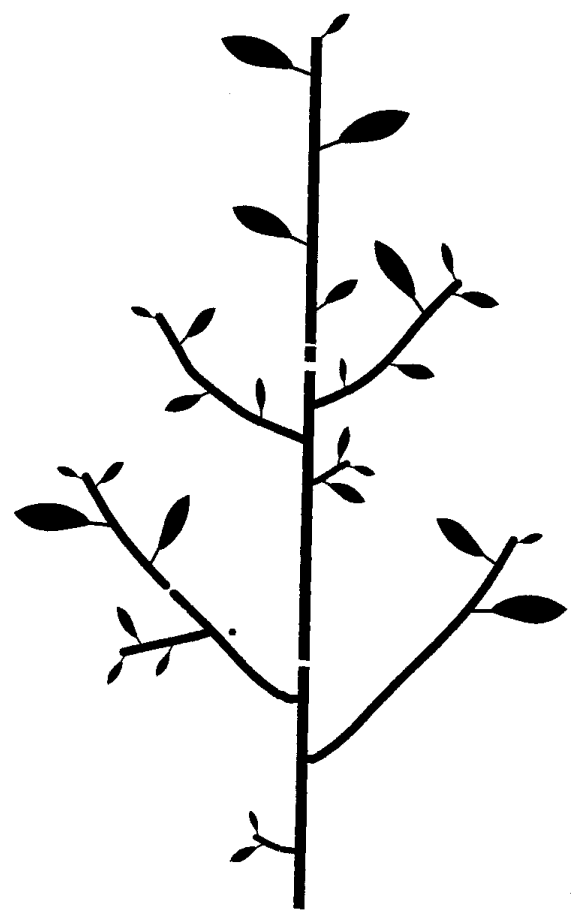

Internodes

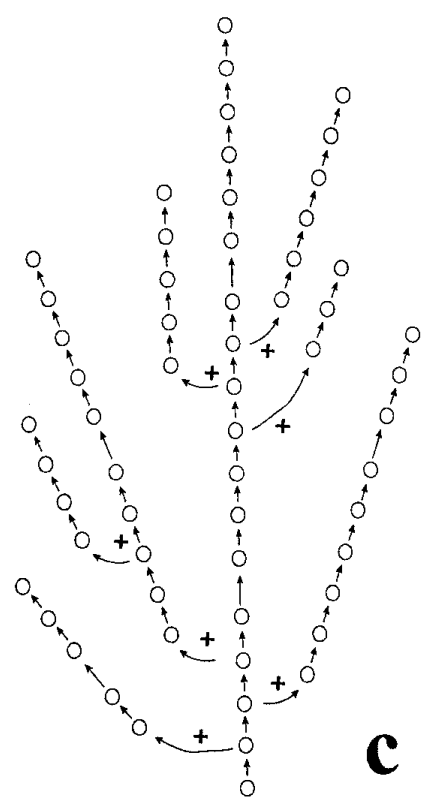

Figure 19. Multiscale tree graphs. The plant can be represented by a tree graph at different scales, e.g. axis scale a. growth unit scale b. and internode scale c. A multiscale-tree graph result from the superposition of all these representations d. (from [52]). 

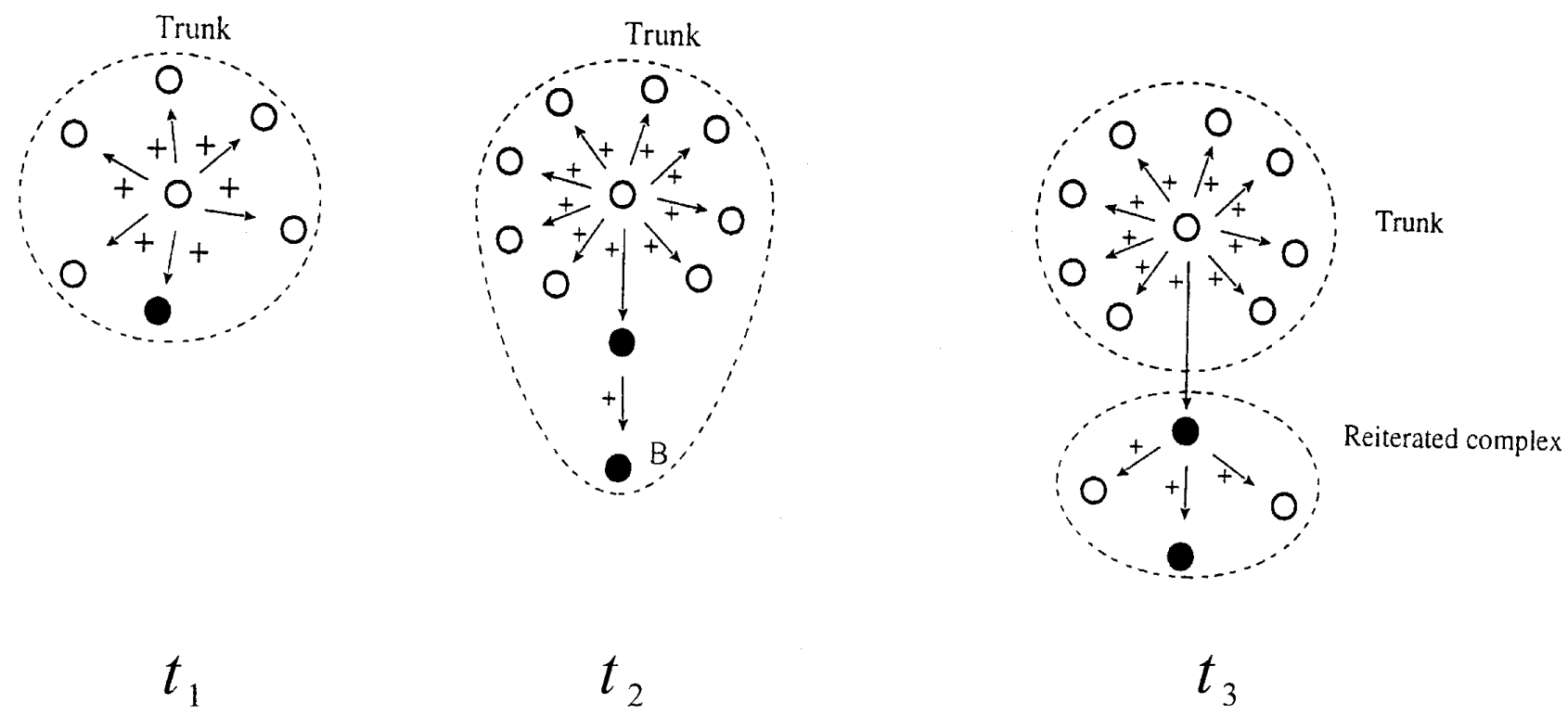

\section{time}

Figure 20. Variation of the decomposition relationship with time in the topological description of a branching system (illustration on the differentiation of a reiterated complex from the trunk of a plant). A trunk is made of several components, here modules for instance. During plant growth, any macroscopic component (such as the trunk $\left(t_{1}\right)$ ) may lose some of its components (in black $\left.\left(t_{2}\right)\right)$ to the benefit of new macroscopic components $\left(t_{3}\right)$ (e.g. a reiterated complex) (from [52]).

A growing plant is represented by a time-varying MTG where each tree graph at any scale is a growing tree graph. Using this formalism, Godin and Caraglio showed that decomposition relationships between components during plant growth may vary over time (figure 20). This property can be used to model the growth of complex structures. MTGs are used in AMAPmod software dedicated to plant architecture measurement and analysis [53, 55, 56], as a central data structure used to organise all the information collected on plants.

\subsection{Multiscale structure encoding}

Multiscale representation of plant architecture is a rather recent issue in plant architecture modelling. Little work has been carried out on encoding such multiscale representations. For plants whose multiscale architecture is generated using fractal-based mechanisms or L-systems, the first possibility consists of reusing the string notation for encoding tree graphs (see Sect. 3). The com- plete string represents the plant containing a maximum of details. From this detailed description, plant description at a coarser scale can be obtained by removing substrings included between square brackets corresponding to high levels of detail from the initial string.

A special encoding scheme has been designed for MTGs to describe the multiscale topology of plants observed in the field [53] (figure 21). Recently, this scheme has been extended to integrate the description of component geometry in a consistent way within the multiscale representation using $3 \mathrm{D}$ digitising $[27,54,112]$. A plant described in this manner can be reconstructed (figure 22) and analysed using AMAPmod software.

\section{DISCUSSION}

In this paper, a wide variety of models for representing plant architectures have been outlined, ranging from global to multiscale representations. These models have been shown to correspond to a few formal 


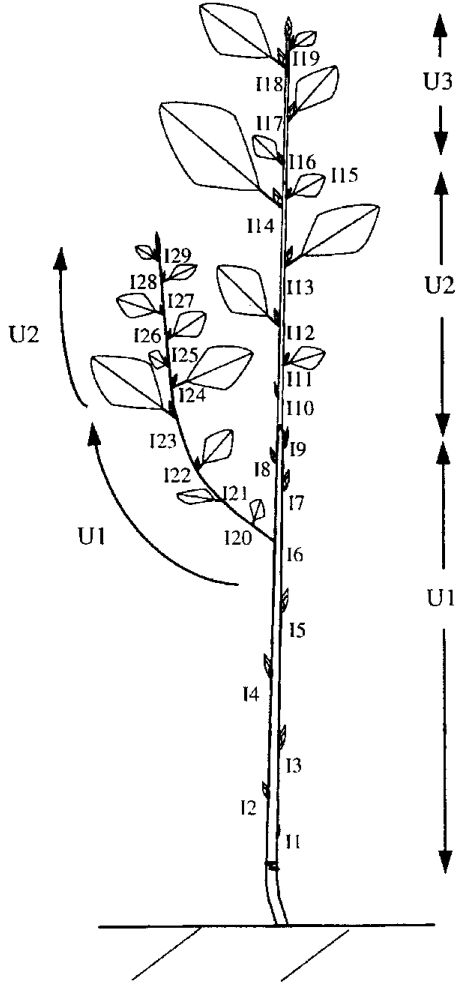

$\mathbf{a}$

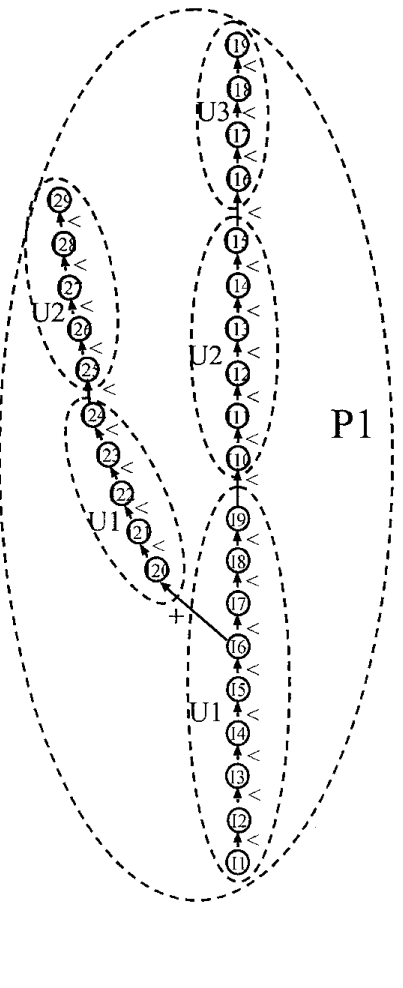

b

\begin{tabular}{|c|c|c|}
\hline & Length & Diameter \\
\hline $\begin{array}{l}/ \mathrm{P} 1 / \mathrm{U} 1 \\
/ \mathrm{I} 1<\mathrm{I} 2<\mathrm{I} 3<\mathrm{I} 4<\mathrm{I} 5<\mathrm{I} 6\end{array}$ & 10 & 5.9 \\
\hline$+U 1$ & 7 & 3.5 \\
\hline $\begin{array}{l}/ \mathrm{I} 20<\mathrm{I} 21<\mathrm{I} 22<\mathrm{I} 23<\mathrm{I} 24<\mathrm{U} 2 \\
/ \mathrm{I} 25<\mathrm{I} 26<\mathrm{I} 27<\mathrm{I} 28<\mathrm{I} 29\end{array}$ & 4 & 2.1 \\
\hline $\begin{array}{l}<\mathrm{I} 7<\mathrm{I} 8<\mathrm{I} 9<\mathrm{U} 2 \\
/ \mathrm{I} 10<\mathrm{I} 11<\mathrm{I} 12<\mathrm{I} 13<\mathrm{I} 14<\mathrm{I} 15<\mathrm{U} 3 \\
/ \mathrm{I} 16<\mathrm{I} 17<\mathrm{I} 18<\mathrm{I} 19\end{array}$ & $\begin{array}{c}8 \\
7.5\end{array}$ & $\begin{array}{l}4.3 \\
3.9\end{array}$ \\
\hline
\end{tabular}

c

Figure 21. Encoding multiscale plant architecture representations. a. the plant is decomposed into components at different scales. b. A MTG formally represents this decomposition $\mathbf{c}$. The MTG is encoded using a string notation [53].

representations. Tree graph representations are at the core of modular representations (when topology is taken into account) whereas multiscale tree graph representations play a similar role for multiscale representations.

The three types of plant architecture representation described in this paper, namely the global, modular and multiscale representations, actually correspond to an increasing degree of robustness.

Non-robust models are those that work solely for the goal for which they were initially designed. A change of goal requires at least a modification in the model or more drastically a change of model. This is the case for instance in global models which reduce to a minimum the plant representation, taking account of the modelling objective and nothing more. Because of their restricted range of use, non-robust models are often concise. By contrast, robust models have the ability to adapt to objectives for which they were not initially designed. In this sense, modular representations of plant architecture are more robust than global representations since the decom- position of the architecture into basic components makes it possible to support more applications. They are, however, less concise.

If we assume, for example, that the geometrical parameters for every component in the modular representation of a plant's architecture are known, this representation may be used without modification in various applications: estimating light interception in crowns [31, $113,117]$, modelling water/assimilate fluxes through the plant architecture [32, 51], realistic 3D rendering of plants [34, 95], modelling the mechanical strengths in branches [50], computing the distribution of component geometric and topological characteristics in crowns [27] or in root systems [29, 70, 87], making spatial statistics in the tree crown [5], studying the motion of insects on stems [62], estimating the distribution of water under a vegetal canopy during rain, modelling the node structure in $\log$ sections [67], and more. The robustness of modular representations is a key factor supporting their increasingly frequent use in modelling applications. 

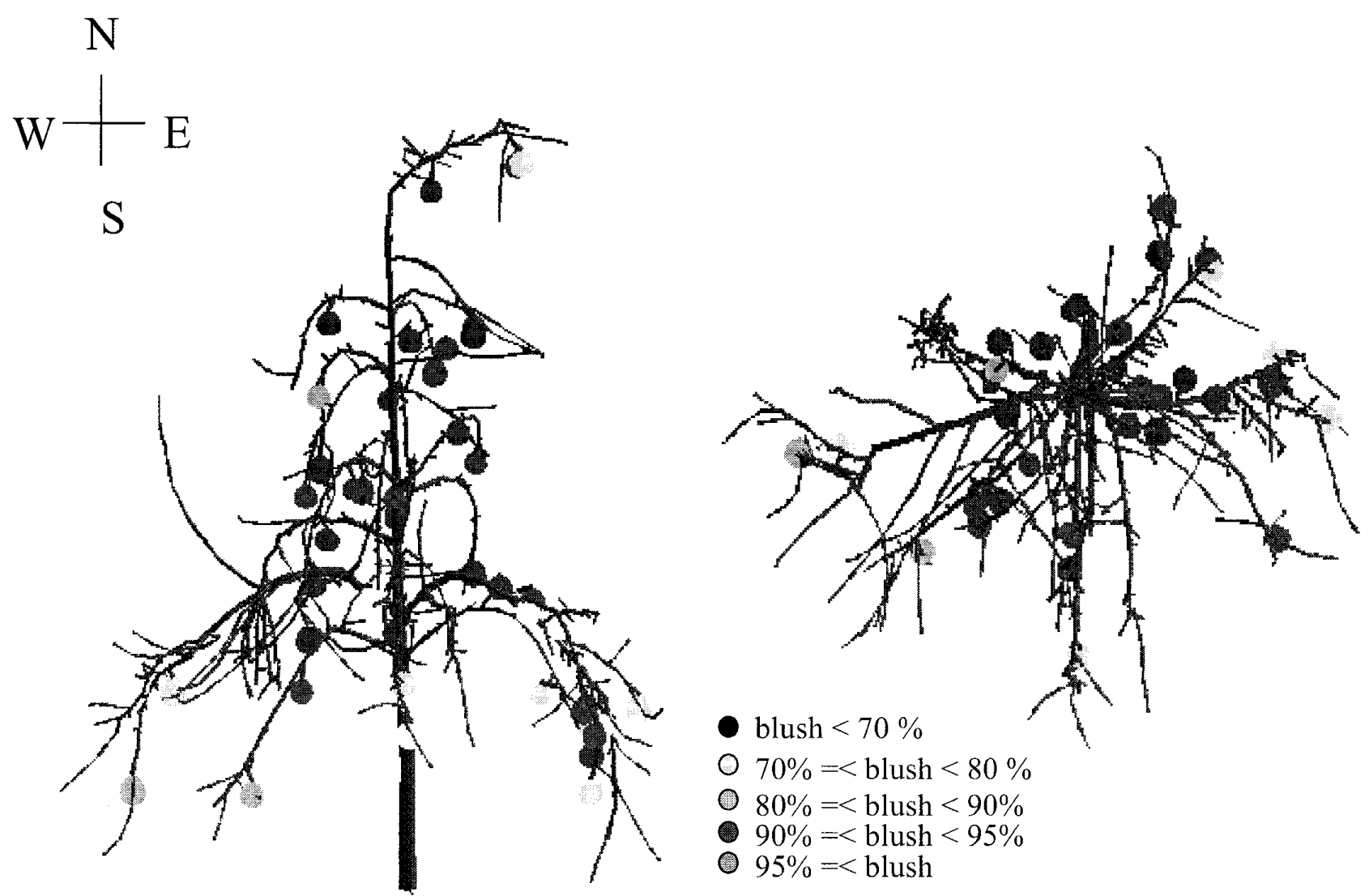

Figure 22. Side and top view of a digitised tree in a multiscale context. The representation contains both geometric and multiscale topological information. Fruit attributes (like red colouring or "blush") can be analysed according to their architectural context (from [27]).

Multiscale representations are even more robust than modular representations since they contain more structural information. They potentially allow the user to address different scales of space or time within a modelling application. However, they are also more complex, which limits their current use in plant modelling. Nonetheless, current research in plant modelling highlights the need to integrate information at different scales in plant architecture representations $[8,27,56,88,100]$. Such a growing consensus should favour the use of multiscale representation of plants in future structure/function models. This will only be the case if adequate tools and models are built to handle these complex plant representations.

As underlined by this review of the literature, modular representations are currently the most widely used representation in plant structural-functional modelling. They currently correspond to the best compromise between complexity and robustness. However, the interest in developing global or multiscale representations is increasing. On the one hand, scaling up models from plant individuals to forest stands requires global and efficient representations of plant architecture. On the other hand, a detailed understanding of plant growth, at different time scales, relies on the modelling of plant architecture at different spatial scales.

The choice of a plant architecture representation is often associated with the problem of collecting plant architecture data in the field. This can be used either to analyse different types of distributions within plant architecture, to define reference data for building plant structure/function models or initial data for simulations of plant growth, or to assess model output compared with actual data. The increasing interest of the research community in plant structure/function models makes the collection of plant architecture data an increasingly important issue. However, collecting architecture data requires the definition of complex experimental and observation protocols. This is a time-consuming task (e.g. 
[54]) and the apparent heterogeneity of plant architecture representations, discussed above, makes it difficult to collect architecture information in the field in a reusable way.

The research community currently lacks such reusable databases and associated tools. However, we have shown in this paper that there are actually only a few different formalisms to represent plant architecture and that tools to deal with such representations are emerging, e.g. [1, $43,54,55,62,72,75,91,93]$. This suggests that a task of primary importance for the plant modelling community is to define i) translation schemes to exchange plant architecture data and ii) common data formats and tools to create standard plant architecture database systems that could be shared by research teams, with different modelling goals, throughout the world.

Acknowledgements: I would like to thank E. Costes, H. Sinoquet, Y. Guédon and F. Houllier and for their fruitful comments on the first version of this paper.

\section{REFERENCES}

[1] Adam B., Sinoquet H., Godin C., 3A version 1.0 : Un logiciel pour l'Acquisition de l'Architecture des Arbres, intégrant la saisie simultanée de la topologie au format AMAPmod et de la géométrie par digitalisation 3D, Guide de l'utilisateur, Clermont-Ferrand, France, INRA-PIAF, 1999.

[2] Ahuja R.K., Magnanti T.L., Orlin J.B., Network flows. Theory, algorithms, and applications, Prentice Hall, Upper Saddle River, New Jersey, USA, 1993.

[3] André J.P., A study of vascular organization of Bamboos (Poaceae-Bambuseae) using a microcasting method, IAWA Journal 19, 3 (1998) 265-278.

[4] Arneodo A., Argoul F., Bacry E., Elezgaray J., Muzy J.F., Ondelettes, multifractales et turbulences - de l'ADN aux croissances cristallines, Diderot Editeur, Paris, France, 1995.

[5] Audergon J.M., Monestiez P., Habib R., Spatial dependences and sampling in a fruit tree: a new concept for spatial prediction in fruit studies, J. Horticult. Sci. 68, 1 (1993) 99-112.

[6] Baker C.J., The development of a theoretical model for the windthrow of plants, J. Theor. Biol. 175, 3 (1995) 355-372.

[7] Banegas F., Michelucci D., Roelens M., Jaeger M., Canovas F., Hierarchical automated clustering of cloud point set by ellipsoidal skeleton, Application to organ geometric modeling from CT-scan images, in: SPIE's International Symposium on Medical Imaging 1999, San Diego, USA, 1999, in press.

[8] Barczi J.F., de Reffye P., Caraglio Y., Essai sur l'identification et la mise en oeuvre des paramètres nécessaires à la simulation d'une architecture végétale : le logiciel AMAPsim, in: Bouchon J., de Reffye P., Barthélémy D. (Eds.), Modélisation et Simulation de l'Architecture des Végétaux, INRA Éditions, Paris, France, 1997, pp. 205-254.

[9] Barnsley M.F., Fractals everywhere, Academic press, Boston, 1988.
[10] Barthélémy D., Edelin C., Halle F., Architectural concepts for tropical trees, in: Holm-Nielsen L.B., Nielsen I.C., Balslev E. (Eds.), Symposium on Tropical Forests, Academic Press, London, Aarhus, Danemark, 1989, pp. 89-100.

[11] Barthélémy D., Edelin C., Halle F., Canopy architecture, in: Raghavendra A.S. (Ed.) Physiology of trees, John Wiley and Sons Inc., 1991, pp. 1-20.

[12] Bell A.D., The simulation of branching patterns in modular organisms, Phil. Trans. R. Soc. London 313 (1986) 143159.

[13] Bell A.D., Plant form, An illustrated guide to flowering plant morphology, Oxford University Press, Oxford, 1991.

[14] Bell A.D., Roberts D., Smith A., Branching patterns: the simulation of plant architecture, J. Theor. Biol. 81 (1979) 351375.

[15] Bertin N., Environnement climatique, compétition pour les assimilats et modélisation de la nouaison de la tomate en culture sous serre, Ph.D. Thesis, INRA, Paris Grignon, 1993.

[16] Birnbaum P., Modalités d'occupation de l'espace par les arbres en forêt guyanaise, Ph.D. Thesis, Université Paris VI, Paris, France, 1997.

[17] Blaise F., Simulation du parallélisme dans la croissance des plantes et applications, Ph.D. Thesis, Université Louis Pasteur (ULP), Strasbourg, France, 1991.

[18] Blaise F., Barczi J.F., Jaeger M., Dinouard P., de Reffye P., Simulation of the growth of plants. Modeling of metamorphosis and spatial interactions in the architecture and development of plants, in: Kunii T.L., Luciani A. (Eds.), Cyberworlds, John Wiley \& Sons, Ltd, Tokyo, Japon, 1998, pp. 81-109.

[19] Borchert R., Honda H., Control of development in the bifurcating branch system of Tabeduia rosea: a computer simulation, Botanical Gazette 145, 2 (1985) 184-195.

[20] Bouchon J., de Reffye P., Barthélémy D. (Eds.), Modélisation et simulation de l'architecture des végétaux, INRA Éditions, Paris, France, 1997.

[21] Caraglio Y., Edelin C., Architecture et dynamique de la croissance du platane, Platanus hybrida Brot. (Platanaceae) \{syn. Platanus acerifolia (Aiton) Willd.\}, Bulletin de la Société Botanique de France, Lettres botaniques 137, 4-5 (1990) 279291.

[22] Cescatti A., Modelling the radiative transfer in discontinuous canopies of asymmetric crowns. I. Model structure and algorithms, Ecol. Modell. 101 (1997) 263-274.

[23] Chelle M., Développement d'un modèle de radiosité mixte pour simuler la distribution du rayonnement dans les couverts végétaux, Ph.D. Thesis, Université de Rennes I, Rennes, France, 1997.

[24] Chen S.G., Ceulemans R., Impens I., A fractal-based Populus canopy structure model for the calculation of light interception, For. Ecol. Manag. 69, 1-3 (1994) 97-110.

[25] Chen W.K., Applied graph theory, North Holland Publ. Co., Amsterdam, The Netherlands, 1976.

[26] Cluzeau C., Dupouey J.L., Courbaud B., Polyhedral representation of crown shape, A Geometric tool for growth modelling, Ann. Sci. For. 52 (1995) 297-306.

[27] Costes E., Sinoquet H., Godin C., Kelner J.J., 3D digitizing based on tree topology: application to study the variability of apple quality within the canopy, Acta Horticulturae (1999) in press. 
[28] Damez C., Application de la méthode de radiosité aux simulations botaniques, Mémoire de DEA Imagerie, vision et Robotique, Paris, INAPG, 1998.

[29] Danjon F., Sinoquet H., Godin C., Colin F., Drexhage M., Characterisation of structural tree root architecture using 3D digitising and AMAPmod software, Plant Soil 211, 2 (1999) 241-258.

[30] Dauzat J., Simulated plants and radiative transfer simulations, in: Varlet-Grancher C., Bonhomme R., Sinoquet H. (Eds.), Colloque Structure du Couvert Végétal et Climat Lumineux: méthodes de caractérisation et applications, INRA Editions, Saumane, France, 1993, pp. 271-278.

[31] Dauzat J., Eroy M.N., Simulating light regime and intercrop yields in coconut based farming systems, Eur. J. Agron. 7 (1997) 63-74.

[32] Dauzat J., Rapidel B., Berger A., Simulation of leaf transpiration and sap flow in virtual plants: description of the model and application to a coffee plantation in Costa Rica, Agricult. For. Meteor. (1999) in press.

[33] de Reffye P., Dinouard P., Barthélémy D., Architecture et modélisation de l'Orme du Japon Zelkova serrata (Thunb.) Makino (Ulmaceae): la notion d'axe de référence, in: De la forêt cultivée à l'industrie de demain, $3^{\mathrm{e}}$ Colloque Sciences et Industries du Bois, Arbora, Bordeaux, France, 1990, pp. 351352.

[34] de Reffye P., Edelin C., Françon J., Jaeger M., Puech C., Plant models faithful to botanical structure and development, in: SIGGRAPH'88, Atlanta, USA, 1988, pp. 151-158.

[35] de Reffye P., Fourcaud T., Blaise F., Barthélémy D., Houllier F., A functional model of tree growth and tree architecture, Silva Fenn. 31, 3 (1997) 297-311.

[36] de Reffye P., Houllier F., Blaise F., Fourcaud T., Essai sur les relations entre l'architecture d'un arbre et la grosseur de ses axes végétatifs, in: Bouchon J., de Reffye P., Barthélémy D. (Eds.), Modélisation et Simulation de l'Architecture des Végétaux, INRA Éditions, Paris, France, 1997, pp. 255-423.

[37] Deleuze C., Houllier F., A transport model for tree ring width, Silva Fenn. 31, 3 (1997) 239-250.

[38] Deussen O., Hanrahan P., Lintermann B., Mech R., Pharr M., Prunsinkiewicz P., Realistic modeling and rendering of plant ecosystems, in: SIGRAPPH'98, ACM, Orlando, Florida, USA, 1998.

[39] Diggle A.J., ROOTMAP-A model in three-dimensional coordinates of the growth and structure of fibrous root systems, Plant Soil 105 (1988) 169-178.

[40] Edelin C., The monopodial architecture: the case of some trees species from tropical Asia, Research Pamph. 105 (1990).

[41] Ewers F.W., Cruiziat P., Measuring water transport and storage, in: Lassoic J.P., Hinckley T.M. (Eds.), Techniques and approaches in forest tree physiology, CRC Press, Boca Raton, USA, 1991, pp. 91-115.

[42] Falconer K., Fractal geometry: mathematical foundation and applications, John Wiley \& Sons, Chichester, 1990.

[43] Ferraro P., Godin C., A distance measure between plant architectures, Ann. For. Sci. 57 (2000) 445-461.

[44] Fisher J.B., How predictive are computer simulations of tree architecture?, Int. J. Plant Sci. 153, 3 (1992) 137-146.
[45] Fisher J.B., Weeks C.L., Tree architecture of Neea Nyctaginaceae: geometry and simulation of branches and the presence of two different models, Bull. Mus. Hist. Nat. 7 (1985) 385-401.

[46] Fitter A.H., The topology and geometry of plant root systems: influence of watering rate on root system topology in Trifolium pratense, Ann. Botany 58 (1986) 91-101.

[47] Fitter A.H., An architectural approach to the comparative ecology of plant root systems, New Phytologist 106 (Suppl.) (1987) 61-77.

[48] Ford E.D., Avery A., Ford R., Simulation of branch growth in the Pinaceae: interactions of morphology, phenology, foliage productivity, and the requirement for structural support, on the export of carbon, J. Theor. Biol. 146 (1990) 15-36.

[49] Fourcaud T., Analyse du comportement mécanique d'une plantes en croissance par la méthode des éléments finis, $\mathrm{Ph} . \mathrm{D}$. Thesis, Université de Bordeaux I, Bordeaux, France, 1995.

[50] Fourcaud T., Lac P., Mechanical analysis of the form and internal stresses of a growing tree by the finite element method, in: Engin A.E. (Ed.) PD-Vol. 77, Engineering Systems Design Analysis Proceedings, ASME, 1996, pp. 213-220.

[51] Früh T., Simulation of water flow in the branched tree architecture, Silva Fenn. 31, 3 (1997) 275-285.

[52] Godin C., Caraglio Y., A multiscale model of plant topological structures, J. Theor. Biol. 191 (1998) 1-46.

[53] Godin C., Costes E., Caraglio Y., Exploring plant topology structure with the AMAPmod software: an outline, Silva Fenn. 31, 3 (1997) 355-366.

[54] Godin C., Costes E., Sinoquet H., A method for describing plant architecture which integrates topology and geometry, Ann. Botany 84 (1999) 343-357.

[55] Godin C., Guédon Y., Costes E., Exploration of plant architecture databases with the AMAPmod software illustrated on an apple-tree hybrid family, Agronomie 19, 3-4 (1999) 163184.

[56] Godin C., Guédon Y., Costes E., Caraglio Y., Measuring and analyzing plants with the AMAPmod software, in: Michalewicz M.T. (Ed.) Plants to ecosystems - Advances in Computational Life Sciences, 2nd International Symposium on Computer Challenges in Life Science, CSIRO Australia, Melbourne, Australia, 1997, pp. 53-84.

[57] Gondran M., Minoux M., Graphs and algorithms, Wiley-Interscience, New-York, 1984.

[58] Gouyet J.F., Physique et structures fractales, Masson, Paris, France, 1992.

[59] Greene N., Voxel space automata: modeling with stochastic growth processing in voxel space, Comp. Graph. 23, 3 (1989) 175-184.

[60] Hallé F., Modular growth in seed plants, Phil. Trans. R. Soc. London 313 (1986) 77-87.

[61] Hallé F., Oldeman R.A.A., Tomlinson P.B., Tropical trees and forests, An architectural analysis, Springer-Verlag, New-York, 1978.

[62] Hanan J.S., Room P.M., Practical aspects of plant research, in: Michalewicz M.T. (Ed.) Plants to ecosystems Advances in Computational Life Sciences, 2nd International Symposium on Computer Challenges in Life Science, CSIRO publishing, Melbourne, Australia, 1997, pp. 28-43. 
[63] Harper J.L., Rosen B.R., White J., The growth and form of modular organisms, The Royal Society, London, UK, 1986.

[64] Hill D.R.C., Object-oriented analysis and simulation, Addison-Wesley Publ. Co., Harlow, UK, 1996.

[65] Honda H., Description of the form of trees by the parameters of the tree-like body: Effects of the branching angle and the branch length on the shape of the tree-like body, J. Theor. Biol. 31 (1971) 331-338.

[66] Jaeger M., Représentation et simulation de la croissance des végétaux, Ph.D. Thesis, Université Louis Pasteur (ULP), Strasbourg, France, 1987.

[67] Jaeger M., Leban J.M., Chemouny S., Saint André L., 3D stem reconstruction from CT scan exams, in: Biological improvement of wood properties, Third Workshop IUFRO WP S5.01-04, La Londe-Les-Maures, France, 1999, accepted.

[68] Janssen J.M., Lindenmayer A., Models for the control of branch positions and flowering sequences of capitula in Mycelis muralis (L.) Dumont (Compositae), New Phytologist 105 (1987) 191-220.

[69] Johnson R.S., Lakso A.N., Approaches to modeling light interception in orchards, HortScience 26, 8 (1991) 10021004.

[70] Jourdan C., Rey H., Modelling and simulation of the architecture and development of the oil-palm (Elaeis guineensis Jacq.) root system. I. The model, Plant Soil 190 (1997) 217-233.

[71] Keisling T., Counce P., An encoding process for morphological analysis of soybean fruit distribution, Crop Sci. 37 (1997) 1665-1669.

[72] Kurth W., Growth grammar interpreter GROGRA 2.4: A software for the 3-dimentional interpretation of stochastic, sensitive growth grammar in the context of plant modelling, Introduction and Reference Manual, Forschungszentrum Waldokosysteme der Universitat Gottingen, 1994.

[73] Kurth W., Morphological models of plant growth: possibilities and ecological relevance, Ecol. Modell. 75-76 (1994) 299-308.

[74] LeDizès S., Cruiziat P., Lacointe A., Sinoquet H., LeRoux X., Balandier P., Jacquet P., A Model for simulating structure-function relationships in walnut tree growth processes, Silva Fenn. 31 (1997) 313-328.

[75] Lewis P., 3-D plant modelling for remote sensing simulation studies using the Botanical Plantb Modelling System, Agronomie 19, 3-4 (1999) 185-210.

[76] Luck H.B., Luck J., Modélisation du fonctionnement d'un méristème par des L-systèmes et des systèmes de graphes et de cartes à réécriture parallèle, in: Le Guyadère H. (Ed.), Masson, Paris, France, 1987, pp. 375-395.

[77] Mäkelä A.A., Sievänen R.P., Comparison of two shootroot partitioning models with respect to substrate utilization and functional balance, Ann. Botany 59 (1987) 129-140.

[78] Mandelbrot B.B., The fractal geometry of nature, W.N. Freeman, New York, USA, 1983.

[79] Mandelbrot B.B., Fractals, in: Meyers R.A. (Ed.) Encyclopedia of physical science and technology, Academic Press, Orlando, Florida USA, 1987.

[80] McMurtrie R.E., Forest productivity in relation to carbon partitioning and nutrient cycling: a mathematical model, in: Cannell M.G.R., Jackson J.E. (Eds.), Attributes of trees as crops plant, ITE, Monks Wood, Abbots Ripton, Hunts, UK, 1985 , pp. 194-207.

[81] Mitchell K.J., Dynamics and simulated yield of Douglas-fir, For. Sci. 21, 4 (1975) 1-39.

[82] Newman W.I., Turcotte D.L., Gabrielov A.M., Fractal trees with side branching, Fractals 5, 4 (1997) 603-614.

[83] Nikinmaa E., Analyses of the growth of scots pine; matching structure with function, Acta For. Fenn. 235 (1992) 368.

[84] Norman J.M., Welles J.M., Radiative transfer in an array of canopies, Agronomy J. 75 (1983) 481-488.

[85] Oosterhuis L., Oldeman R.A.A., Sharik T.L., Architectural approach to analysis of North American temperate deciduous forests, Canadian J. For. Res. 12, 4 (1982) 835-847.

[86] Oppenheimer P.E., Real time design and animation of fractal plants and trees, in: Evans D.C., Athay R.J. (Eds.), SIGGRAPH'86, ACM, Dallas, Texas USA, 1986, pp. 55-64.

[87] Pagès L., Root system architecture: from its represention to the study of its elaboration, Agromonie 19, 3/4 (1999) 295-304.

[88] Perttunen J., Sievänen R., Nikinmaa E., Salminen H., Saarenmaa H., Väkevä J., LIGNUM: a tree model based on simple structural units, Ann. Botany 77 (1996) 87-98.

[89] Preparata F., Yeh R., Introduction to discrete structures for computer science and engineering, Addison-Wesley, Reading Menlo Park London, 1973.

[90] Press W.H., Teukolsky S.A., Vetterling W.T., Flannery B.P., Numerical recipes in C. The art of scientific computing, 2nd ed., Cambridge University Press, Cambridge, 1996.

[91] Prusinkiewicz P., (project leader), Virtual Plant Laboratory. A hypertext document and software distribution, http://www.cpsc.ucalgary.ca/projects/bmv/vlab/index.html (1996).

[92] Prusinkiewicz P., Modeling of spatial structure and development of plants: a review, Scientia Horticult. 74 (1998) 113-149.

[93] Prusinkiewicz P., Hammel M., Hanan J., Mech R., Lsystem: from the theory to visual models of plants, in: Michalewicz M.T. (Ed.) Plants to Ecosystems. Advances in Computational Life Sciences, I, CSIRO publishing, Melbourne, 1997, pp. 1-27.

[94] Prusinkiewicz P., Hanan J., Lindenmayer systems, fractals, and plants, Springer Verlag, New-York, 1989.

[95] Prusinkiewicz P., James M., Mech R., Synthetic topiary, in: Computer Graphics Proceedings, 1994, pp. 351-358.

[96] Prusinkiewicz P., Lindenmayer A., The algorithmic beauty of plants, Springer Verlag, New York, 1990.

[97] Prusinkiewicz P., Remphrey W.R., Davidson C.G., Hammel M.S., Modeling the architecture of expanding Fraxinus pennsylvanica shoots using L-systems, Canadian J. Botany 72 (1994) 701-714.

[98] Rao S.S., The finite element method in engineering., 3rd ed, Butterworth Heinemann, Boston, USA, 1999.

[99] Remphrey W.R., Neal B.R., Steeves T.A., The morphology and growth of Arctostaphylos uva-ursi bearberry: an architectural model simulating colonizing growth, Canadian J. Botany 61 (1983) 2451-2458. 
[100] Remphrey W.R., Prusinkiewicz P., Quantification and modelling tree architecture, in: Advances in computational life sciences, Vol. I: Plants to Ecosystems, CSIRO, Australia, 1997, pp. $45-52$.

[101] Rey H., Godin C., Guedon Y., Vers une représentation formelle des plantes, in: Bouchon J., de Reffye P., Barthélémy D. (Eds.), Modélisation et Simulation de l'Architecture des Végétaux, INRA Éditions, Paris, France, 1997, pp. 139-171.

[102] Robinson D.F., A symoblic framework for the description of tree architecture models, Botan. J. Linn. Soc. 121 (1996) 243-261.

[103] Room P.M., Maillette L., Hanan J.S., Module and metamer dynamics and virtual plants, Adv. Ecol. Res. 25 (1994) 105-157.

[104] Ross J.K., The radiation regim and the architecture of plant stands, Junk W. Pubs., The Hague, The Netherlands, 1981.

[105] Salminen H., Saarenmaa H., Pertunen J., Sievänen R., Väkevä J., Nikinmaa E., Modelling trees using and object-oriented scheme, Math. Comp. Model. 20, 8 (1994) 49-67.

[106] Shimizu H., Heins R.D., Computer vision based system for plant growth analysis, Trans. ASAE 38, 3 (1995) 959964.

[107] Shinozaki K., Yoda K., Hozumi K., Kira T., A quantitative analysis of plant. The Pipe Model theory I, Jpn. J. Ecol. 14, 3 (1964) 97-105.

[108] Shinozaki K., Yoda K., Hozumi K., Kira T., A quantitative analysis of plant. The Pipe Model theory. I. Basic analyses, Jpn. J. Ecol. 14, 3 (1964) 97-105.

[109] Sillion F.X., Hierarchical solution techniques for realistic rendering, in: State of the Art Report - Graphicon'95 Conférence, St Petersburg, Russia, 1995.

[110] Sinoquet H., Adam B., Rivet P., Godin C., Interactions between light and plant architecture in an agroforestry walnut tree, in: Agroforestry Forum, 1998, pp. 37-40.

[111] Sinoquet H., Bonhomme R., Modeling raditive tranfer in mixed and row intercropping systems, Agricult. For. Meteor. 62 (1992) 219-240.

[112] Sinoquet H., Rivet P., Godin C., Assessment of the three-dimensional architecture of walnut trees using digitising, Silva Fenn. 31, 3 (1997) 265-273.

[113] Sinoquet H., Thanisawanyangkura S., Mabrouk H., Kasemsap P., Characterisation of the light environment in canopies using 3D digitising and image processing, Ann. Botany 82 (1998) 203-212.

[114] Smith A.R., Plants, fractals, and formal languages, Comp. Graph. 18, 3 (1984).

[115] Smith G.S., Curtis J.P., Edwards C.M., A Method for analysing plant Architecture as it relates to fruit quality using three-dimensional computer graphics, Ann. Botany 70 (1992) 265-269.

[116] Sperry J.S., Adler F.R., Campbell G.S., Comstock J.P., Limitation of plant water use by rhizosphere and xylem con- ductance: results from a model, Plant Cell Environ. 21 (1998) 347-360.

[117] Takenaka A., A simulation model of tree architecture development based on growth response to local light environment, J. Plant Res. 107 (1994) 321-330.

[118] Tarjan R.E., Data structures and network algorithms, Society for Industrial and Applied Mathematics, Phyladelphia, Pennsilvania, USA, 1983.

[119] Thornley J.H.M., A model to describe the partitioning of photosynthate during vegetative plant growth, Ann. Botany 33 (1969) 419-430.

[120] Thornley J.H.M., A balanced quantitative model for root:shoot ratios in vegetative plants, Ann. Botany 36 (1972) 431-441.

[121] Thornley J.H.M., Johnson I.R., Plant and crop modeling: a mathematical approach to plant and crop physiology, Oxford University Press, New York, 1990.

[122] Tricot C., Courbes et dimensions fractales, SpringerVerlag, Paris, 1993.

[123] Tyree M.T., Ewers F.W., The hydraulic architecture of trees and other woody plants, New Phytolology 119 (1991) 345360 .

[124] Valentine H.T., Tree-growth models: dérivations employing the Pipe-model theory, J. Theor. Biol. 117, 4 (1985) 579-585.

[125] Viennot X.G., Eyrolles G., Janey N., Arquès D., Combinatorial analysis of ramified patterns and computer imagery of trees, in: SIGGRAPH' 89 , ACM, Boston, USA, 1989, pp. 31-40.

[126] Watson C.E., Bourland F.M., COTMAP, an interactive microcomputer program for mapping plant structure and fruiting patterns of cotton, in: J.M B. (Ed.) Proceedings of the Beltwid Cotton Production Research Conferences, Menphis, USA: National Cotton Council of America, Nashwille, USA, 1989, pp. 131-134.

[127] Weber J., Penn J., Creation and rendering of realistic trees, in: Computer Graphics Proceedings, Annual Conference Series, Acm Siggraph, 1995, pp. 381-394.

[128] White J., The plant as a metapopulation, Ann. Rev. Ecol. Syst. 10 (1979) 109-145.

[129] Zeide B., Fractal geometry and forest measurements, in: LaBau V.J., Cunia T. (Eds.), The state-of-the-art methodology of forest inventory, USDA Forest Service, 1990, pp. 260266.

[130] Zeide B., Fractal geometry in forestry applications, For. Ecol. Manag. 46 (1991) 179-188.

[131] Zeide B., Pfeifer P., A methode for estimation of fractal dimension of tree crown, For. Sci. 37, 5 (1991) 1253-1265.

[132] Zimmermann M.H., Hydraulic architecture of some diffuse-porous trees, Canadian J. Botany 56 (1978) 2286-2295. 